\title{
Comparison of the Calculated Drought Return Periods Using Tri-variate and Bivariate Copula Functions under Climate Change Condition
}

Elaheh Motevalibashi Naeini ( $\sim$ mbnaeini.e@gmail.com )

Shahid Chamran University https://orcid.org/0000-0002-4689-2521

Ali Mohammad Akhoond-Ali

Shahid Chamran University of Ahvaz

Fereydoun Radmanesh

Shahid Chamran University of Ahvaz

Jahangir Abedi Koupai

Isfahan University of Technology College of Agriculture

Shahrokh Soltaninia

College Lane Campus: University of Hertfordshire

\section{Research Article}

Keywords: Drought Return Period, Climate Change, Copula Function, Drought Map

Posted Date: April 9th, 2021

DOI: https://doi.org/10.21203/rs.3.rs-242023/v1

License: (9) This work is licensed under a Creative Commons Attribution 4.0 International License. Read Full License 
1 Comparison of the Calculated Drought Return Periods Using Tri-variate and Bivariate

2 Copula Functions under Climate Change Condition

3 Elaheh Motevali Bashi Naeini ${ }^{\mathrm{a}^{*}}$, Ali Mohammad Akhoond-Ali ${ }^{\mathrm{a}}$, Fereydoun Radmanesh ${ }^{\mathrm{a}}$, $4 \quad$ Jahangir Abedi Koupai ${ }^{\mathrm{b}}$, Shahrokh Soltaninia ${ }^{\mathrm{c}}$

5 a Department of Hydrology and Water Resources, Faculty of Water Sciences Engineering,

6 Shahid Chamran University of Ahvaz, Iran.

7 d Department of Water Engineering, College of Agriculture, Isfahan University of

8 Technology, Isfahan, Iran

9 Department of Biological \& Environmental Sciences University of Hertfordshire College

10 Lane Hatfield Hertfordshire AL10 9AB United Kingdom

$11{ }^{*}$ Corresponding author: Elaheh Motevali Bashi Naeini, email:_mbnaeini.e@gmail.com

\section{Abstract}

Concerning the various effects of climate change on intensifying extreme weather phenomena all around the world, studying its possible consequences in the following years has attracted the attention of researchers. As the drought characteristics identified by drought indices are highly significant in investigating the possible future drought, the Copula function is employed in many studies. In this study, the two- and three-variable Copula functions were employed for calculating the return period of drought events for the historical, the near future, and the far future periods. The results of considering the two- and three-variable Copula functions were separately compared with the results of the calculated Due to the high correlation between drought characteristics, bivariate and trivariate of Copula functions were applied to evaluate the return periods of the drought. 
The most severe historical drought was selected as the benchmark, and the drought zoning map for the GCM models was drawn. The results showed that severe droughts can be experienced, especially in the upper area of the basin where the primary water resource is located. Also, the nature of the drought duration plays a decisive role in the results of calculating the return periods of drought events.

Keywords: Drought Return Period, Climate Change, Copula Function, Drought Map

\section{Introduction}

31 Drought occurs for long periods of unusual hydrological conditions resulting in a sharp

32 decline in rainfall. Fundamentally, drought is an aridity type caused by the decrease in rainfall. Meteorological measurements are the first sign of a drought (Bazarafshan 2017; Abdulkadir 2017; Khan et al. 2018). All climate conditions may experience this phenomenon (Chen et al. 2013). Moreover, extreme weather events, such as drought, are the main causes of risk to agricultural systems (Ben-Ari et al. 2016; Hernandez-Barrera et al. 2017; Pascoa et al. 2017; Zampieri et al. 2017; Ribeiro et al. 2018). Drought analysis is mostly done by calculating its characteristics, such as drought duration and severity, via drought indices (Yang 2010; Liu et al. 2016). Analyzing drought indices are important for assessing the drought conditions because the incident provides various methods to determine drought severity, arrival (Cahng et al. 2016; Hao et al. 2016; Tian et al. 2018; Mukherjee et al. 2018).

42 Some indices are the Standardized Precipitation Index (SPI), the Reconnaissance Drought 43 Index (RDI), the modified SPI index, and the Joint Deficit Index (JDI). The values of modified SPIs are integrated with different time scales through multiple Copula distribution

45 functions and create the JDI to determine the overall drought situation in the JDI (Kao and 46 Govindarajo 2010; Ma et al. 2016). The SPI is proper for measuring meteorological drought 
47 since it is based on precipitation data. As climate change could cause extreme hydrological 48 phenomena, investigating its effects is one of the necessities of water resources management

49 (Ahmadalipour et al. 2017; Oguntunde et al. 2017). In the northern hemisphere, areas

50 between latitudes 15 and 45 degrees are susceptible to more severe droughts (Mousavi 2005;

51 Barlow et al. 2016; Gazol et al. 2016).

52 Research has been done for investigating the effects of climate change on the drought via several drought indices (Mathbout et al. 2018; Thomas and Prasannakumar 2016; Lee2017 et al. 2017; Bazrafshan et al. 2017). Examples include the SPI and the RDI, the Percent of Normal Precipitation Index (PNPI), the Agricultural Rainfall Index (ARI), the Multivariate Standardized Drought Index (MSDI), and JDI Index, having utilized for drought analysis in different parts of the world including Iran (Bazrafshan et al. 2017; Hoffman et al. 2009, Kirono et al. 2011, Selvaraju and. Baas 2007, Lee et al. 2013, Serinaldi et al. 2009; Mirabbasi et al. 2013; MirAbbasi et al. 2013; Madadgar and Moradkhani 2011; Lee et al. 2013; Kirono et al. 2011; Srinaldi et al. 2009; Hoffman et al. 2009; Selavarajo and Bass 2007).

There is a significant correlation between duration and severity of droughts (Ayantobo et al. 2019; Santos et al. 2019; Wu et al. 2017; Ayantobo et al. 2017; Madadgar and Moradkhani 2011). Drought analysis based on just one characteristic can only cause a misunderstanding of droughts. By calculating the return period only based on one drought characteristic ignores all other drought characteristics and their relevant characteristics (Ge et al. 2016; Thilakarathne and Sridhar 2017). Besides, the return period of a drought can be measured as a sample for the severity larger than a certain value. Nevertheless, the return period cannot provide information on other drought characteristics, such as drought duration (Taskirirs et al. 2016; Kwon and Lall 2016). Planning for a longer period needs more reflection. Also, it is crucial to plan for the happening years in advance occasionally. Therefore, knowing about the 
71 return period of drought along with paying attention to the drought characteristics for managing water resources is vital (Zhang et al. 2017). Several trivariate copula functions were conducted for multivariate frequency analysis of extreme hydrological events such as droughts (Maddadgar and Moradkhani 2011; Chen et al. 2011; Hao et al. 2017; Hangshing and Dabral 2018; Zhu et al. 2019). Contrary to conventional methods such as normal multivariate distribution, the Copula function is independent of marginal distribution functions, so that any type of marginal distribution function can be considered for each of the variables (Da Rocha Júnior et al. 2020; Zhang and Singh 2007; Favre et al. 2004). Also, the current drought index and the copula-based analysis of drought properties present a new concept for appropriate management practices in the changing environment (Das et al. 2019). Investigating the use of Copula functions, such as Gumbel, Frank, Clayton, and Gaussian, in analyzing drought characteristics, Lee et al. (2013) calculated the SPI in four stations of Canada and Iran and utilized Copula functions for analyzing the drought. Wang et al. (2010) employed a trivariate Copula to analyze the drought characteristics in the New South Wales area of Australia. They calculated the SPI to assess the characteristics of the drought. Dashe et al. (2019) coupled the hydrological Soil Water Assessment Tool (SWAT) with the multivariate copulas for prediction of the drought years. The results showed that the developed SWAT-Copula-based method has can be employed in data-scarce regions for effective drought monitoring with the minimum observed inputs. Daneshkhah et al. (2016) and Luo et al. (2019) constructed a different flood risk management model via the Copulabased Bayesian network to analyze the flood risk. Ribeiro et al. (2019) employed the copula theory for estimating joint probability distributions describing the dependence degree between drought conditions and crop yield anomalies of two major rainfed portions of cereal. 
95 Vegetation Condition Index (VCI), and Temperature Condition Index (TCI) are employed.

96 The results showed that while TCI is commonly employed in copula models indicating better

97 probabilities of joint extreme high values of wheat and drought indicators, the VCI and SPEI

98 are related to copula models illustrating higher probabilities of joint extreme low values. Balistrocchi and Grossi (2020) predicted the effect of climate change on urban drainage systems in northwestern Italy via a copula-based approach, finding the seasonal distribution of storms critical for urban drainage systems. Chatrabgoun et al. (2020) used the copula functions in a new mathematical framework with nonlinear analysis, investigated the effects and dangers of frost on the vine. The study revealed that the developed Caspian model is a proper instrument for predicting the return period of glacial events. Kiafar et al. (2020) used the copula-based genetic algorithm method to monitor meteorological droughts of Qazvin station in Iran. The drought characteristics are measured via the monthly SPI. The study shows that drought probabilistic characteristics could be used for water resources management and planning.

The return periods of drought events has been largely ignored in previous drainage basin studies and also some basins face some complications, and providing drought zoning maps will lead to a better understanding of the situation of basins, which has not been sufficiently discussed in previous studies, especially the Zayandeh Rud basin in Iran. Hence the purpose of this study was to employ, the Standardized Precipitation Index (SPI) to calculate the duration, severity, and peak intensity of a drought in the basin throughout history, in the near future, and far future using data from 15 GCM models obtained from the fifth IPCC report (AR5).

\section{Materials and Methods}

\subsection{The SPI}


119 The SPI was developed by McKee et al. (1993). The SPI value can be positive or negative, with positive values indicating periods when precipitation is above the average and negative values indicating periods when precipitation is below the average (Shiau 2006). The SPI also can be calculated for different time scales $(1,3,6,12,24$, and 48 months). While the SPI of 1-3 months is utilized for meteorological drought study, SPI of 1-6 months is applied for agricultural drought study, and the SPI of 6-24 months is employed for hydrological drought determination (World Meteorological Organization 2012). In calculating this index, initially, the gamma distribution function is adjusted to the precipitation data, then the cumulative probability obtained from the gamma distribution is transferred to the normal standard cumulative distribution with an average of zero and a mean deviation of one. Equation (1) is illustrated as the SPI calculation method.

The severity, duration, and peak intensity of drought are calculated based on the RUN theory proposed by Yevjevich (1967). According to this method, the threshold level for determining drought was considered as (-1) to examine more severe drought conditions (Table 1). Since the precipitation data were only available for 30 years, the 3-month SPI calculation was considered to better comprehend seasonal meteorological drought. According to the definition, drought duration means consecutive months in which the SPI value is less than (1). The drought severity is the absolute value of SPI cumulative values in periods when SPI values are consistently less than (-1), and the drought peak intensity is the minimum SPIvalue for every drought event.

140 Distribution functions are utilized to fit drought characteristics including log-normal distribution function, exponential distribution function, gamma distribution function, and 
142 Weibull distribution function. The most suitable distribution functions for drought severity 143 and duration have been determined using the Bayesian information criterion (BIC) method. 144 The relation of BIC calculation is used as $\mathrm{BIC}=-2 \log$ likelihood $+\mathrm{d} \cdot \log (\mathrm{N})$ in which $\mathrm{N}$ is the 145 sample size and $\mathrm{d}$ is the number of parameters; lower the value, better the fitness (Li et al. 146 2013).

147 Table 1- SPI classification

\begin{tabular}{ll}
\hline SPI Value & \multicolumn{1}{l}{$\begin{array}{l}\text { Drought Condi- } \\
\text { tion }\end{array}$} \\
\hline 2.0 and more & Very Wet \\
1.5 to 1.99 & Moderately \\
1.0 to 1.49 & Wet \\
-0.99 to 0.99 & Near Normal \\
-1.0 to -1.49 & Moderately \\
-1.5 to -1.99 & Dry \\
-2 and less & Severely Dry \\
& Extremely Dry \\
\hline
\end{tabular}

$149 \quad 2.2$ The Multivariate Probabilistic Distribution of a Copula Function

150 The Copula function is a multivariate joint function applied to connect various probabilistic 151 distribution functions. Furthermore, a random vector $\left(\mathrm{x}_{1}, \mathrm{x}_{2}, \ldots, \mathrm{X}_{\mathrm{n}}\right)$ with continuous marginal 152 distribution functions of $\mathrm{F}_{\mathrm{i}}(\mathrm{x})=\mathrm{P}\left[\mathrm{X}_{\mathrm{i}} \leq \mathrm{x}\right]$ has been considered. For each member of this 153 random vector, uniform margins $\left(\mathrm{U}_{1}, \mathrm{U}_{2}, \ldots, \mathrm{U}_{\mathrm{d}}\right)$ are available as follows (Nelson 2007): 
155 Therefore, the C Copula function can be defined as a joint distribution function of $\left(\mathrm{U}_{1}, \mathrm{U}_{2}\right.$, $\left.\ldots, \mathrm{U}_{\mathrm{d}}\right)$ for the vector $\left(\mathrm{x}_{1}, \mathrm{x}_{2}, \ldots, \mathrm{x}_{\mathrm{n}}\right)$ :

158 The relation is described as follows:

160 Scalar theory (1959) showed that C Copula function for each n-dimensional cumulative distribution function of $\mathrm{H}$ with different margins $\mathrm{F}_{1}, \ldots, \mathrm{F}_{\mathrm{n}}$ is defined as follows: (Nelson 2007)

$H\left(X_{1}, X_{2}, \ldots, X_{n}\right)=C\left[F_{1}\left(X_{1}\right), F_{2}\left(X_{2}\right), \ldots, F_{n}\left(X_{n}\right)\right]=C\left(U_{1}, U_{2}, \ldots, U_{n}\right)$

In which $\mathrm{u}_{1}, \ldots, \mathrm{u}_{\mathrm{n}}$ is the distribution functions of $\mathrm{X}_{1}, \ldots, \mathrm{X}_{\mathrm{n}}$ (Madadgar and. Moradkhani, 2011).

Marginal functions should be uniform in the 0 and 1 range. Copula functions have different

167 families, and some of them are increasingly used in hydrological studies (Yan 2007).

168 According to the literature review, normal Copula and t Copula were considered to be in the family of elliptical Copulas and Gumble, Frank, and Clayton Copulas were considered in the family of Archimedes Copulas of the Copula functions that had been used in this study (Chen et al. 2013; Yang 2010; Lee et al. 2013; Serinaldi et al. 2009; Mirabbasi et al. ; 2013,

172 Madadgar and Moradkhani, 2011 ; Chen et al. 2011; Chen et al. 2011; Chen et al. 2012; Chen et al. 2011; Madadgar and Moradkhani 2011; Sarinaldi et al. 2009).

\subsection{Return period based on Copula function}

175 It is important to know the frequency of extreme phenomena in hydrological studies. To 176 assess the drought, the time between the arrival of a drought phenomenon and the arrival of 
177 the next drought is called the inter-arrival time, and the mean inter-arrival time of two

178 drought phenomena occurrences is defined as the return period (Srinaldi et al. 2009).

179 In the single variable mode, the return period is calculated as (6) and (7):

$180 \quad \mathrm{~T}_{\mathrm{d}}=\frac{\mathrm{E}(\mathrm{L})}{\mathrm{P}_{\mathrm{D}}(\mathrm{D} \simeq \mathrm{d})}$

$181 \quad \mathrm{~T}_{\mathrm{d}}=\frac{\mathrm{E}(\mathrm{L})}{\mathrm{P}_{\mathrm{S}}(\mathrm{S} \geq \mathrm{s})}$

182 Where $T_{d}$ is the return period of the drought, $E(L)$ is the expected value of the drought's inter-

183 arrival time, $\mathrm{D}$ indicates the duration of the drought, and $\mathrm{S}$ is the severity of the drought. The

184 formula for calculating the return period for a multivariate return period can also be

185 developed based on the method of calculating the return period of a single variable.

186 According to Xia's (2006) method, the calculation of the return period in multivariate mode is

187 done with via two logical operators "and" and "or". The operator "and" indicates the return

188 periods in which all variables are greater than or equal to the specified values, and the

189 operator "or" indicates a state in which at least one of the variables is greater than or equal to

190 the specified values.

191 The return period is calculated for the case of $\mathrm{D} \geq \mathrm{d}$ and $\mathrm{S} \geq \mathrm{s}$, as well as for $\mathrm{D} \geq \mathrm{d}$ or $S \geq S$

192 mode with the help of relations (8) and (9):

193

$\mathrm{T}_{\mathrm{and}}=\frac{\mathrm{E}(\mathrm{L})}{\mathrm{P}(\mathrm{D} \geq \mathrm{d}, \mathrm{S} \geq \mathrm{g})}=\frac{\mathrm{F}(\mathrm{L})}{1-\mathrm{F}_{\mathrm{D}}(\mathrm{d})-\mathrm{F}_{\mathrm{S}}(\mathrm{s})+\mathrm{C}\left[\mathrm{F}_{\mathrm{D}}(\mathrm{d})_{2} \mathrm{~F}_{\mathrm{S}}(\mathrm{s})\right]}$

$194 \quad \mathrm{~T}_{\text {or }}=\frac{\mathrm{E}(\mathrm{L})}{\mathrm{P}(\mathrm{D} \geq \mathrm{d} \text { or } \mathrm{S} \geq \mathrm{B})}=\frac{\mathrm{E}(\mathrm{L})}{1-\mathrm{C}\left[\mathrm{F}_{\mathrm{D}}(\mathrm{d}) \mathrm{F}_{\mathrm{S}}(\mathrm{s})\right]}$

195 The calculation relations of the return period with the help of trivariate Copula functions for

$196 \mathrm{I} \geq \mathrm{i}, S \geq s$ and $D \geq d$ modes, as well as $\mathrm{I} \geq \mathrm{i}$ or $S \geq$ sor $D \geq d$ modes, are as described in (10) and (11): 


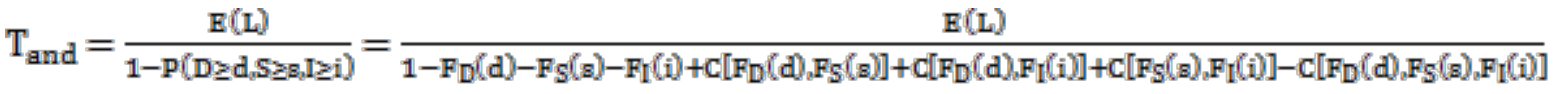

199

200

$\mathrm{T}_{\text {or }}=\frac{\mathrm{E}(\mathrm{L})}{1-\mathrm{P}(\mathrm{D} \geq \mathrm{d} \text { or } \mathrm{S} \geq \mathrm{s} \text { or } \mathrm{I} \geq \mathrm{i})}=\frac{\mathrm{E}(\mathrm{L})}{1-\mathrm{C}\left[\mathrm{F}_{\mathrm{D}}(\mathrm{d}) \mathrm{F}_{\mathrm{S}}(\mathrm{s}), \mathrm{F}_{\mathrm{I}}(\mathrm{i})\right]}$

201 In the above equations, $\mathrm{D}$ indicates the duration of drought, $\mathrm{S}$ indicates the severity of

202 drought, I indicates the peak intensity of drought in each period, d indicates the duration of 203 the determined drought, $\mathrm{s}$ indicates the severity of the specified drought and $\mathrm{i}$ indicates the peak intensity of drought in a period whose value is predetermined.

The return period for drought phenomena, where the duration, severity, and peak intensity of drought are greater than a certain amount, signals a more severe drought phenomenon.

Therefore, the $\mathrm{T}_{\text {and }}$ calculation was considered in this study.

\subsection{Climate Change Scenarios}

209

Investigating climate change in the future includes several factors, such as greenhouse gas emissions, technology development, changes in energy production methods, land use, regional economy, population growth, and more. Various groups are examining these issues under the supervision of the Intergovernmental Panel on Climate Change (IPCC). The Fifth Assessment Report (AR5) was published based on the scenarios of Representative Concentration Pathways (RCP), which represent the pathways for emission and concentration of gases and the obtained results until 2100 (Wayne, 2013). Since AR5 is the latest report released by IPCC, this study employed the data from AR5. The report has defined four RCP scenarios: RCP2.6, RCP4.5, RCP6, and RCP8.5. Two RCP4.5 and RCP8.5 scenarios were selected for this study. The RCP8.5 scenario includes procedures that along with increasing land-use change in agricultural lands and lawns, will also concern the increase in the world's 
population. Therefore, this scenario indicates an increase in greenhouse gas emissions over time, resulting in a high level of greenhouse gas concentrations (Riahi et al. 2007; Riahi et al. 2011). This scenario is similar to the SRES A1F1 scenario compared to the fourth IPCC report scenarios. The RCP4.5 scenario is a scenario in which greenhouse gas emissions are stabilized until 2100 in order not to exceed the desired emission level (Thomson et al. 2011; Wise et al. 2009; Clark et al. 2007; Smith and Wigley 2006). This scenario is similar to the SRES B1 scenario compared to climatic scenarios and emission scenarios in the fourth report (Wayne 2013). NASA has provided researchers with an accuracy of 0.25 degrees and the predicted data of Earth's global daily exchange on the NASA website named NASA Earth Exchange Global Daily Downscaled Projections (NEX-GDDP). The data does not require to be downscaled since it is downscaled for each network on the site (Thrasher et al. 2013). In this study, daily precipitation data for the 30-year historical period from 1979 to 2008 as well as daily precipitation data from 15 GCM models under the RCP4.5 and RCP8.5 scenarios for the next 84-year period of 2016 to 2099 were downloaded from the NASA site.

\subsection{Study Area}

Zayandeh Rud drainage basin is located in Isfahan Province in Iran. The geographical location of this basin has been shown in Figure 1. The basin is a completely closed basin that has no access to the sea. The Zayandeh Rud drainage basin covers an area of 26,917 square kilometers and is located between the latitudes $31^{\circ}-34^{\circ}$ north and longitudes $49^{\circ}-53^{\circ}$ east. Zayandeh Rud River originates from the Zagros Mountain chain in Western Iran and flows into the basin, ending up in Gavkhuni Wetland in the southeast of Isfahan Province (Figure1). The water level of different parts of the basin varies from 1446 meters to 3925 meters, which leads to different climatic conditions in the basin. In general, the mean annual precipitation in the basin is $211 \mathrm{~mm}$, widely varying in annual precipitation in various parts of the basin. 
244 Also, the mean annual potential evapotranspiration in the basin is $1500 \mathrm{~mm}$. The basin's 245 mean annual temperature is (14.5) degrees Celsius with the lowest temperature of $(-12.5)$ 246 degrees Celsius recorded in January and the highest temperature of 42 degrees Celsius 247 recorded in July. Safavi et al. (2014), in a study on the Zayandeh Rud Basin, reported eleven 248 dry years, four normal years, and six wet years between 1991-2011. In a study by Gohari et 249 al. (2013), the effects of climate change on agricultural products and water consumption 250 efficiency in the Zayandeh Rud drainage basin were investigated from 2015-2044. The 251 results showed an annual decrease in the precipitation of 11-31 percent, taking into account 252 changes in precipitation in different months of the year. Furthermore, a study conducted by 253 Sabzevari (2013) showed that recent droughts in the basin have been very devastating in 254 reducing surface water and groundwater resources, especially in the western parts.

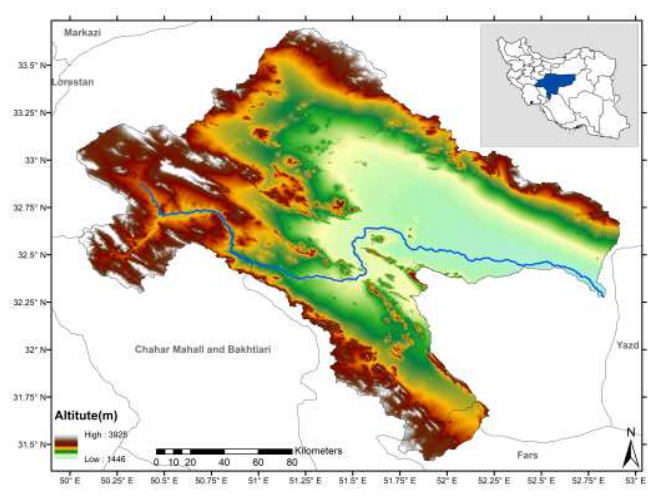

257 Figure 1: Geographic location of the Zayandeh Rud basin 
261 To better understand the pattern of precipitation in the basin, two specific stations were 262 selected at two different points in the basin. One of the stations was upstream and the other 263 was located downstream of the basin. Figure (2) shows the monthly changes in precipitation 264 at the two selected stations. As can be seen in the figure, the amount of precipitation at the 265 upstream station was higher than the amount of precipitation at the downstream station.
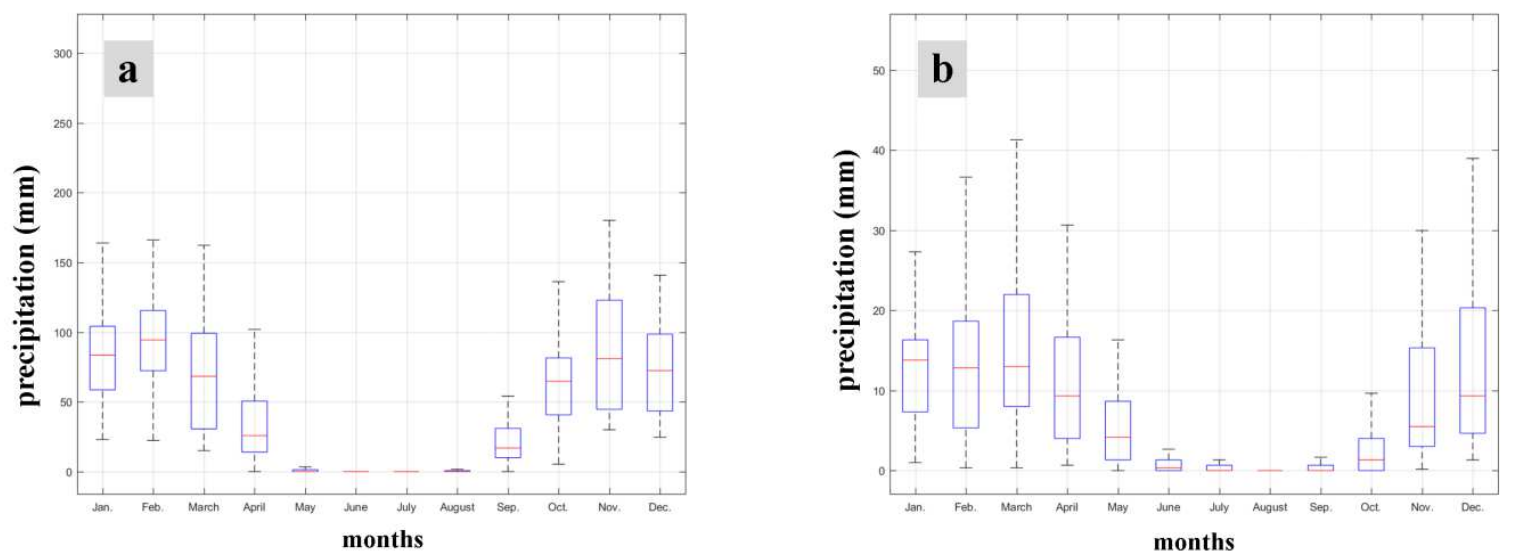

267 Figure 2: Changes in monthly precipitation in the past (1979-2008): a) station located upstream b) station located downstream

\subsubsection{Data Analysis}

271 Zoning of the results on a map is an optimal method to better comprehend the status of the basin. Using such maps, it is easier to study the general condition of the basin and identify the

273 more critical parts of the basin. It was decided to use the existing historical data of NEX274 GDDP, which was available for 57 networks within the basin. 
276 The linear correlation between duration parameters, severity, and peak intensity of drought 277 has been calculated and almost all obtained values were above 0.5 (Figure 3). The correlation 278 range of drought severity and duration was between 0.5 and 0.7 . Also, the correlation between the severity and peak intensity of drought was between 0.8 and 1 , and the correlation between the duration and peak intensity of drought was between 0.4 and 0.7 .

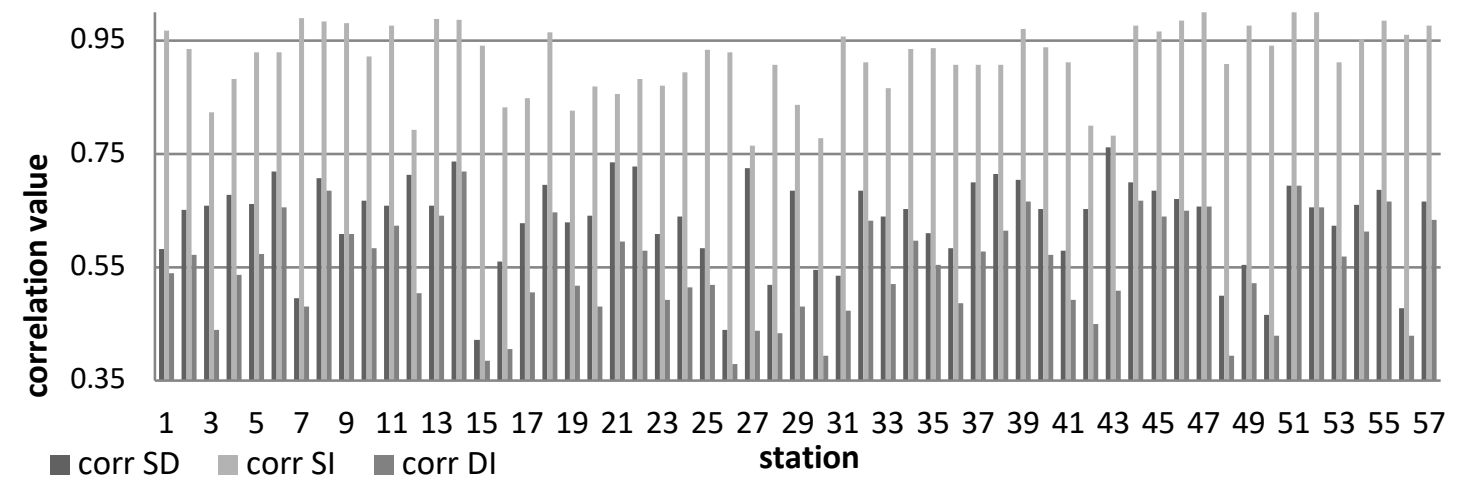

282 Figure 3: Linear correlation between drought characteristics (S indicates severity, D indicates duration, and I indicates the peak intensity of drought in each period.)

According to recent studies, to determine the distribution functions appropriate for each drought characteristic (Xu et al. 2015; Shiau 2006), the Exponential, Gamma, Log-normal, Weibull distribution functions are appropriate for the duration, severity, and peak intensity of the drought. These distribution functions are fitted to calculate drought characteristics in the historical period. The most appropriate function is determined for each station in the basin. For each marginal distribution function, Table (1) has identified the number of stations, in which, the specified distribution function was the best fit for each drought characteristic. Table (2) illustrates the selected distribution functions for each drought characteristic. The maximum likelihood estimation (MLE) method was utilized to estimate function parameters. The BIC method was employed to determine the best function suitable for drought severity, duration, and peak intensity. The assigned functions were also used to extract the severity 
295 distribution functions, drought duration, and peak intensity of drought in the historical and 296 future periods.

297 Table 1: Number of stations with the most appropriate function specified for each drought 298 characteristic

\begin{tabular}{lclll}
\hline & & Gamm & Log- & Weibull \\
Drought & Exponenti & a & normal & distributi \\
characteristics & al function & functio & distributi & \\
& & n & on & on \\
\hline Severity & $\mathbf{6}$ & $\mathbf{1}$ & $\mathbf{4 1}$ & $\mathbf{9}$ \\
\hline Duration & $\mathbf{0}$ & $\mathbf{0}$ & $\mathbf{5 7}$ & $\mathbf{0}$ \\
\hline The Peak Intensity & 52 & $\mathbf{0}$ & $\mathbf{3}$ & $\mathbf{2}$ \\
of drought & & & & \\
\hline
\end{tabular}

300 Table 2: Distribution functions selected for each drought characteristics

\begin{tabular}{lc}
\hline $\begin{array}{l}\text { Drought } \\
\text { characteristics }\end{array}$ & $\begin{array}{c}\text { Selected distributiof } \\
\text { function }\end{array}$ \\
\hline Severity & Log-normal \\
Duration & Log-normal \\
The Peak Intensity of & Exponential \\
drought & \\
\hline
\end{tabular}


303 The most appropriate Copula function for each station in the basin was selected using the

304 BIC method. Table 3 shows the number of stations, where the specified Copula function was

305 the best-calculated function. Table 4 shows the selected Copula functions for severity-

306 duration, the severity-peak intensity of drought, duration-peak intensity of drought, and

307 duration-severity-peak intensity of drought.

308 Table 3: The number of stations with the best-specified Copula functions

duration-severity-maximum

$$
\text { amount of drought }
$$

$\begin{array}{lllll}21 & 32 & 4 & 0 & 0\end{array}$

317 Selected Copula functions

\begin{tabular}{cc}
\hline Copula marginal function & Selected Copula function \\
\hline Severity-Duration & Gumbel \\
\hline Severity-Peak Intensity & Normal \\
\hline Duration-Peak Intensity & Gumbel \\
\hline Duration-Severity-Peak Intensity & Normal
\end{tabular}




\subsection{Effects of Climate Change on the Drought under RCP4.5 S}

322 In this study, $90 \%$ of the highest values of severity, duration, and peak intensity of drought in 323 each period of the historical era were considered as the benchmark severe drought in the 324 basin. Accordingly, the characteristics of the most severe historical drought, which was 325 considered as a criterion for measuring droughts, included the severity of drought with an SPI value of (-4.39), the duration of drought equal to 6 months, and the peak intensity in each

327 period with an SPI value of (-1.36). Considering these characteristics, the drought's return

328 period was calculated for all points of the network within the basin for the historical period 329 (1979-2008), the near future (2016-2057), and the distant future (2058-2099). The results 330 were displayed in spatial maps in the GIS software using the inverse distance weighting 331 (IDW) method. Low values indicated more drought occurrence. According to the results of 332 frequency analysis with the help of the bivariate and trivariate Copula function, the return 333 period of the most severe drought in different parts of the basin is based on all three types of 334 bivariate and trivariate Copula varied between 2 to 500 years. Due to the varied topography 335 in different parts of the basin, this range was logical for the return period. According to 336 Figure (4) which shows the results for the historical period (1979-2008), it is clear that most 337 parts of the basin suffered from severe drought in this historical period (drought severity less than (-4.39) and drought duration more than six months and peak intensity less than $(-1.36)$ with a return period of fewer than 10 years. 


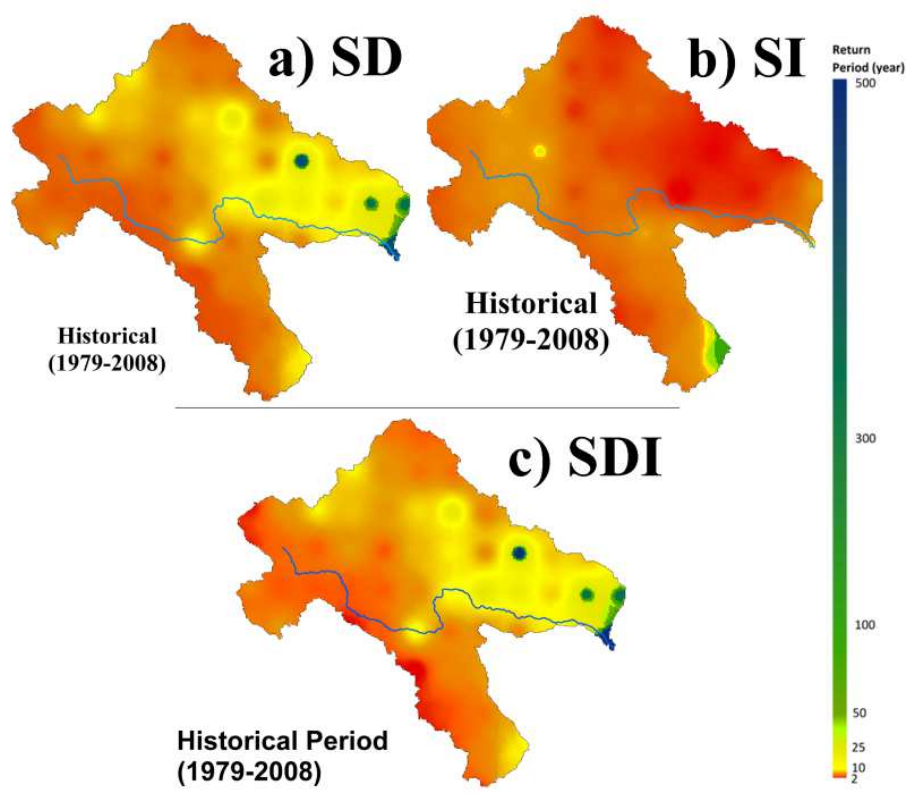

343 Figure 4: Comparison of the calculated return period of the severe drought using tri-variate 344 and bivariate copula functions in the historical period (1979-2008) a) SD: bivariate copula of

345 Severity-Duration b) SI: bivariate copula of Severity-Peak intensity and c) SDI: tri-variate copula of Severity-Duration-Peak intensity.

\section{2 scenarios}

348 According to the Fifth Evaluation Report published by IPCC, the RCP4.5 scenario indicated a stabilized emission of greenhouse gases. Using the output data of GCM models under the RCP4.5 scenarios, the amount of SPI, as well as the severity and duration and peak intensity of drought for all network points within the basin were calculated based on the obtained SPIs.

352 Then the Log-normal distribution function was adjusted to the values of severity and duration and the Exponential distribution function was adjusted to the values of the peak intensity of the drought. Finally, using the bivariate Gumbel Copula function for the severity-duration Copula, the bivariate normal Copula function for the severity-peak intensity of the drought 
and the tri-variate normal Copula function for the severity-duration-peak intensity of the drought, the return period of the most severe drought in the network points within the basin was obtained and the zoning map was drawn for each model.

359 The spatial map of the drought return period for GCM models under the RCP4.5 scenario had 360 been drawn based on the return period calculated with the three mentioned Copulas for the near future (2016-2057) as shown in Figure (5). In the bivariate severity-duration Copula during this period, the GFDL-ESM2M model showed almost similar to or a little worse conditions as the drought conditions during the historical period. Other models showed better conditions; regarding the intended severe drought, they showed less occurrence frequency than the historical period. Most of the used GCM models predicted the occurrence frequency of the intended severe drought to be about 25 years. In some models. the return period of severe drought in the major part of the basin was about 50 years. In the bivariate Copula of severity- peak intensity of the drought, the period of intended severe drought was less than 5 years in all models. This means that up to once every 5 years, a severe drought with an SPI value of less than (-4.39) and a peak intensity of drought with an SPI value of less than (1.36) was likely in the basin. During this period, the CNRM-CM5 model showed drought conditions almost similar to the drought conditions during the historical period. In the trivariate Copula of the severity-duration-peak intensity of the drought, the GFDL-ESM2M model in this period showed the drought conditions almost similar to or a little worse than the historical period in the basin. Most models predicted the severe drought return period in the basin to be less than 25 years. In other words, the occurrence frequency of severe droughts varied from less than 10 years in the past to less than 25 years in the future. 


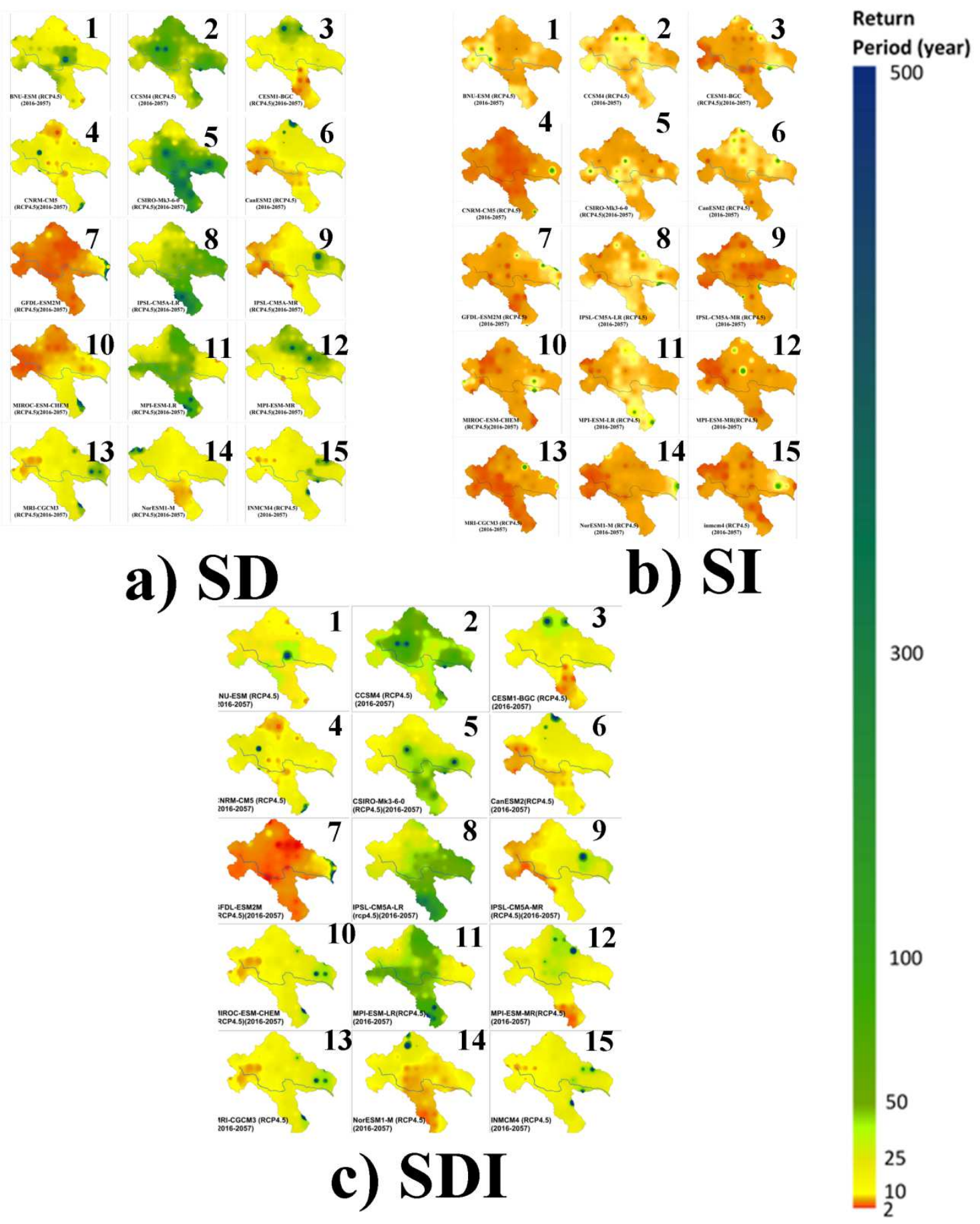

379 Figure5: Comparison of the calculated return period of the severe drought using tri-variate 380 and bivariate copula functions in the near future (2016-2057) using 15 GCMs with RCP4.5 381 a) SD: bivariate copula of Severity-Duration b) SI: bivariate copula of Severity-Peak intensity and c) SDI: tri-variate copula of Severity-Duration-Peak intensity. 
383 The spatial analysis of the drought return period for GCM models under the RCP4.5 scenario calculated with the three mentioned Copula for the distant future (2058-2099) is shown in Figure (6). In the bivariate severity-duration Copula, in the GFDL-ESM2M model, the entire basin was exposed to severe drought and the frequency of severe drought was less than 5 years. Other GCM models predicted a lower occurrence frequency of the severe drought, and in some cases, the return period was calculated to be more than 50 years for the severe drought. In the bivariate Copula of the severity-peak intensity of drought, the results of the GFDL-ESM2M model indicated similar or a little better conditions to historical conditions. In this model, the whole basin was exposed to severe drought and the occurrence frequency of severe drought was less than 3 years. Other GCM models predicted a lower occurrence frequency of the severe drought, and the probability of intended severe drought has increased to less than 5 years. As shown in this figure, in the tri-variate Copula of the severity-durationpeak intensity of the drought, the range of changes in the severe drought frequency from the 15 GCM models under the RCP4.5 scenario in the distant future (2058-2099) was much greater. The results of the GFDL-ESM2M model showed that the entire basin will be prone to severe drought with a frequency of fewer than 2 years. Other GCM models predicted a lower frequency for severe droughts and in some cases, the return period of severe droughts was extended to more than 50 years.

\subsection{Effects of Climate Change on the Drought under RCP8.5 Scenario}

402 According to the previous section, zoning maps from the above calculations were also prepared based on the RCP8.5 scenario. The effects of climate change on the drought based on the data from GCM models under the RCP8.5 scenario for the near future (2016-2057) are shown in Figure (7). In the bivariate Copula of the severity-duration, most GCM models predicted a longer return period than in the past for possible severe droughts in the near 
407 future, which meant less occurrence of the frequency of this drought. In general, according to 408 the results of the GCM models used under the RCP8.5 scenario in the near future, a return 409 period of about 25 years is expected for the severe drought in the basin. In the bivariate 410 Copula of the severity-peak intensity of drought, most GCM models predicted a higher return 411 period than the past for possible severe droughts in the near future, which meant less 412 occurrence of the frequency of this drought. In general, according to the results of the GCM 413 models used under the RCP8.5 scenario in the near future, a return period of about less than 41410 years is expected for severe drought in the basin. In the tri-variate Copula of the severity415 duration-peak intensity of the drought, while in the central part of the basin, the severe 416 drought return period was less than the historical period in this area. Most GCM models 417 predicted a more severe drought return period for the near future than the historical period, 418 indicating a lower occurrence frequency of severe drought than the historical period, with 419 some models even reaching a 50-year return period. 


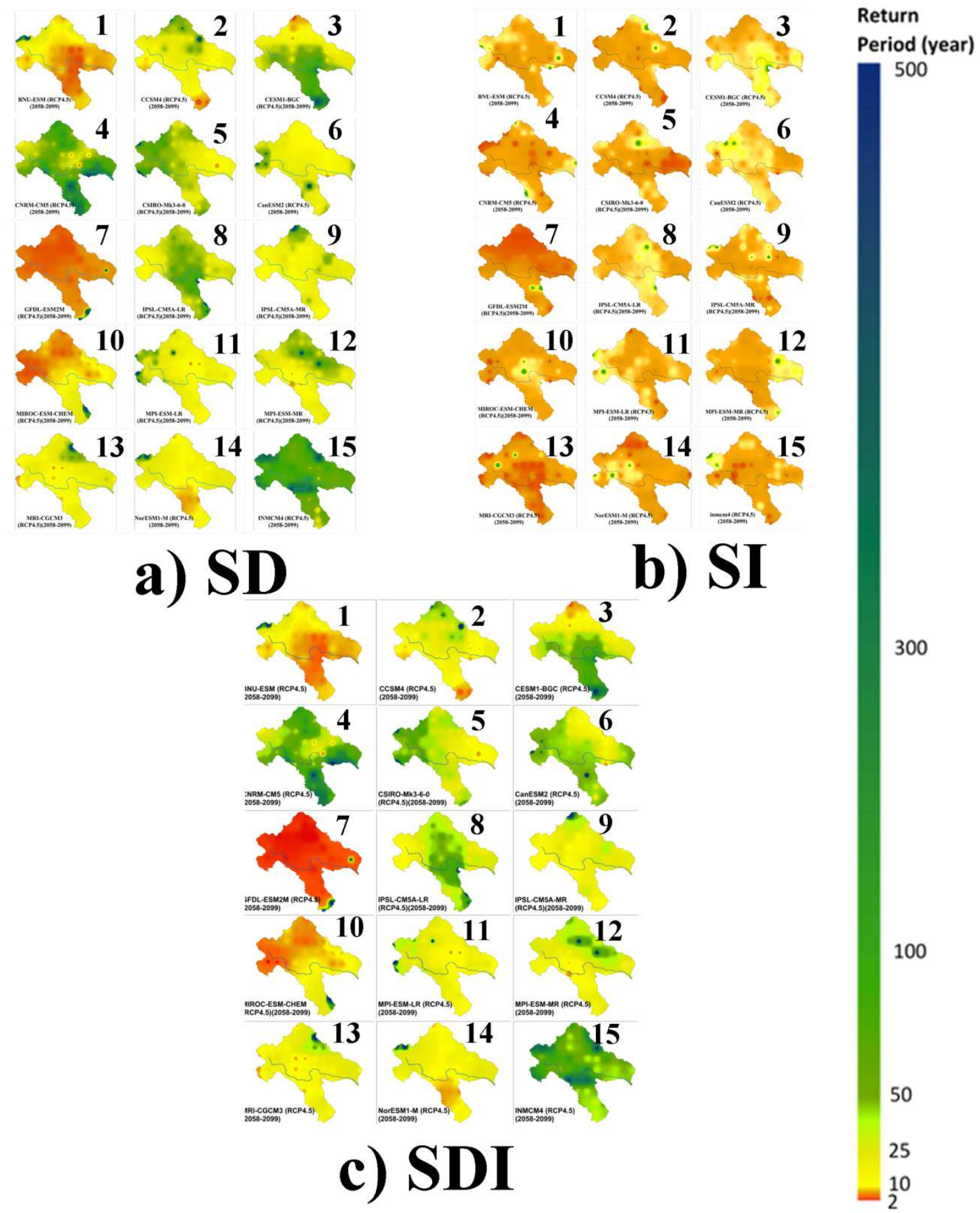

421 Figure 6: Comparison of the calculated return period of the severe drought using tri-variate 422 and bivariate copula functions in the distant future (2058-2099) using 15 GCMs with RCP4.5 423 a) SD: bivariate copula of Severity-Duration b) SI: bivariate copula of Severity-Peak intensity 424 and c) SDI: tri-variate copula of Severity-Duration-Peak intensity. 


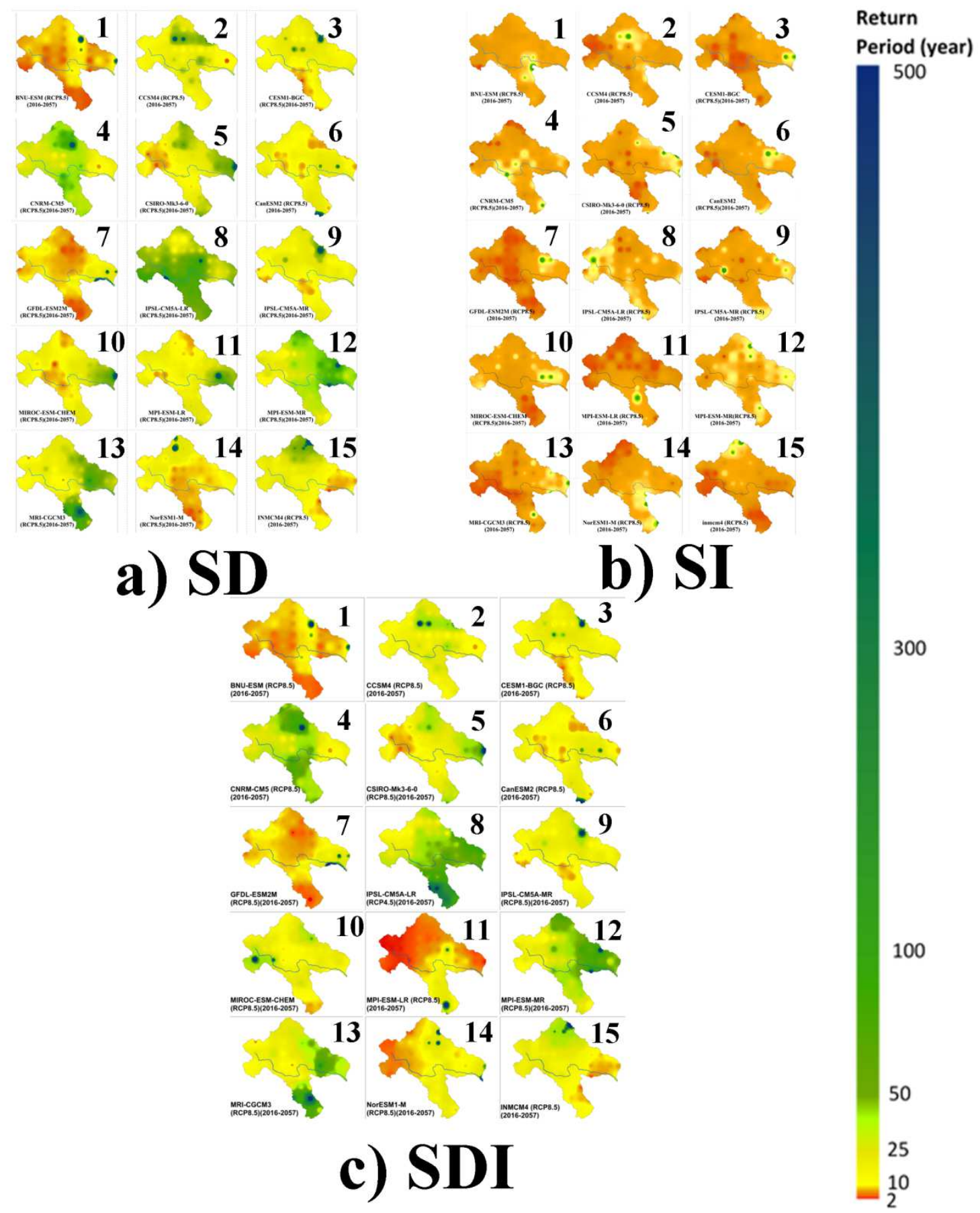

426 Figure 7: Comparison of the calculated return period of the severe drought using tri-variate

427 and bivariate copula functions in the near future (2016-2057) using 15 GCMs with RCP8.5 a)

428 SD: bivariate copula of Severity-Duration b) SI: bivariate copula of Severity-Peak intensity 429 and c) SDI: tri-variate copula of Severity-Duration-Peak intensity. 
431 The effects of climate change on the drought based on the data from GCM models under the

432 RCP8.5 scenario for the distant future (2058-2099) are shown in Figure (8). In the bivariate

433 Copula of severity-duration, the range of variations in the return period of the calculation 434 varied from about less than 10 years to about 400 years. Some models predicted a return 435 period of more than 100 years. Other models predicted a return period of about 25 years for 436 the severe drought intended for the basin. In the bivariate Copula of severity - peak intensity 437 of the drought, the CanESM2 model predicted conditions similar to those of the historical 438 period. Other models predicted a return period of about 10 years for the intended severe 439 drought. Depending on the tri-variate Copula of the severity-duration-peak intensity of 440 drought, the range of return period values in the distant future for the intended basin varies 441 between 10 years to 400 years. In the CESM1-BGC and the IPSL-CM5A-MR models, the 442 return period of severe drought has been more than 100 years for almost all parts of the basin, 443 and the decrease in the occurrence frequency of severe drought in the basin is predicted. 444 Other GCM models predicted a return period of about 25 years for the severe drought in the 445 basin.

446 Based on the results of the calculations performed with the help of bivariate Copula of 447 severity-duration, the drought return period in the near and distant future for the basin 448 increases from less than 10 years to about 25 years compared to the historical period. 449 According to the bivariate Copula of the severity-peak intensity of drought, the return period 450 of the drought in the near and distant future for the basin increases from less than 5 years to 451 more than 10 years compared to the historical period. The results did not provide information 452 on the duration and durability of the severe drought. Without the knowledge of the duration 453 of each drought, planning for water resources is difficult and inaccurate. According to the tri- 
454 variate Copula of the severity-duration-peak intensity of the drought in each period, the return

455 period of the drought in the distant future for the basin increases from less than 10 years to 456 more than 25 years compared to the historical period. Based on GCM models, despite the 457 slight increase in precipitation in the future, due to the uncertainty of climate change 458 forecasts, it is recommended to have a comprehensive water resources management plan in 459 the basin to deal with long-term severe droughts. 

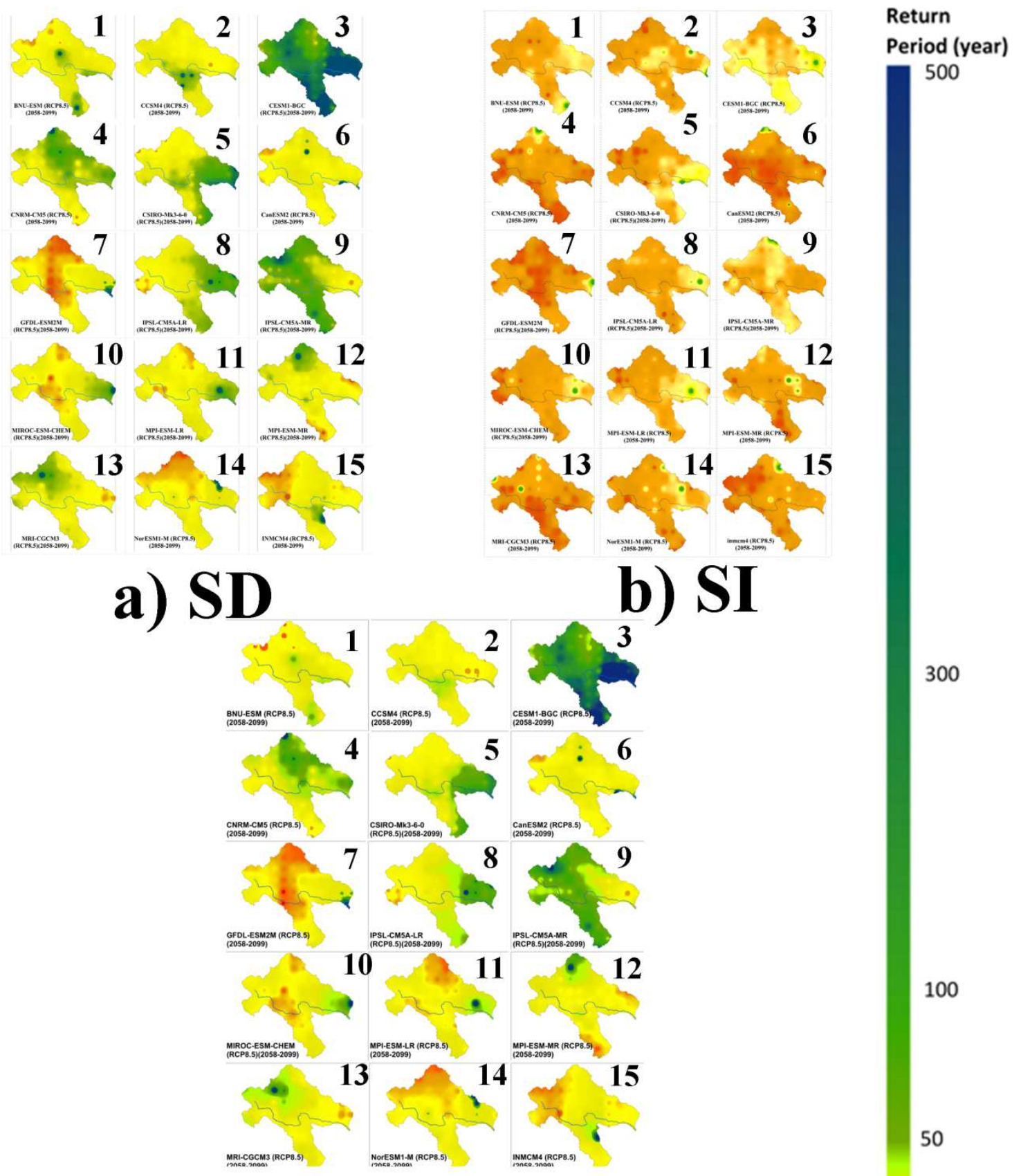

c) SDI

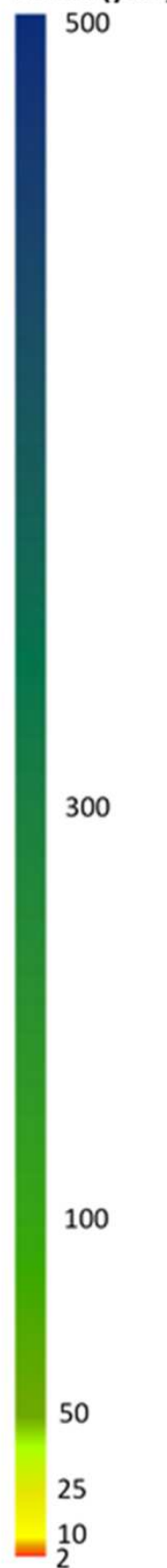

461 Figure 8: Comparison of the calculated return period of the severe drought using tri-variate 462 and bivariate copula functions in the distant future (2058-2099) using 15 GCMs with RCP8.5 463 a) SD: bivariate copula of Severity-Duration b) SI: bivariate copula of Severity-Peak intensity and c) SDI: tri-variate copula of Severity-Duration-Peak intensity. 
3.4 Frequency Analysis of the Most Severe Drought using Bivariate and Tri-variate

\section{Copula Functions}

468 According to the results of the drought frequency analysis with the help of bivariate Copula 469 functions of severity-duration, severity-peak intensity, and the tri-variate Copula of the severity-duration-peak intensity of the drought, it is quite clear that the results of bivariate Copula function of severity-duration and tri-variate Copula of the severity-duration-peak 472 intensity were very close to each other, with similar results for the analysis of historical 473 drought as well as the drought in the near and distant future. However, the results of drought analysis with the help of bivariate Copula of severity- peak intensity, was very different from the results of the previous two Copulas and predicted severe droughts occurring with more frequency.

477 Figure (9) shows the return period of the severe drought based on different drought parameters in the historical period (1979-2008). As shown in the figure, the calculated return period based on the tri-variate Copula was larger. This means that the occurrence frequency of severe drought with higher values than the specified values of severity, duration, and peak intensity, was less. After that, the highest value of the return period results was obtained based on the drought analysis using the bivariate Copula of the duration-peak intensity. Then, the results of the bivariate Copula of the severity-duration were most similar to the tri-variate Copula, and three modes obtained the return period of severe drought for the basin more than other models. The bivariate Copula of severity- peak intensity, showed a lower return period for the relevant drought, and as shown in the figure, the results were more consistent with the results of the calculation of the drought return period based on only one of the variables of 
488 the severity of peak intensity. The implications of this figure and the results suggest that the 489 duration of the drought plays a large role in the drought level return period in the basin, and 490 the higher the intended continuity and duration of drought, the higher the return period for 491 that drought. While the basin has been exposed to a high frequency of drought occurrences,

492 these droughts have not lasted long and have been short-lived.

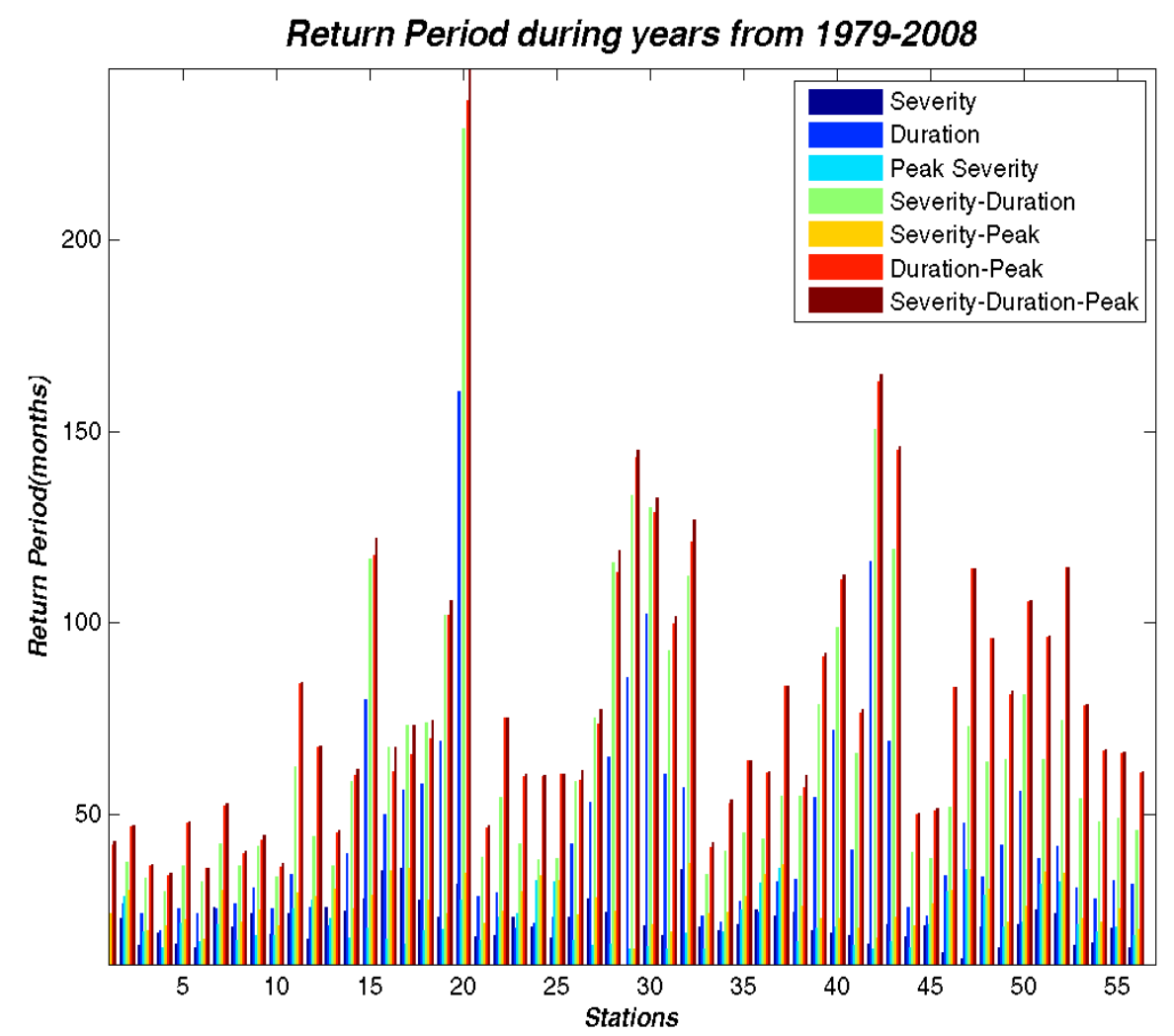

493

494 Figure 9: Return period of severe drought based on various drought parameters in the

495 Historical Period (1979-2008)

\section{Conclusion}

497 As mentioned, drought is an extreme phenomenon that has far-reaching effects on agriculture 498 and water resources. Considering simultaneously the phenomenon of climate change and 499 drought, different effects are expected depending on the location and environmental 
conditions of the region. Therefore, assessing the effects of climate change on the drought is of particular importance to water resource planners. In this study, three main steps have been considered, which are: 1) Calculating the duration, severity, and peak intensity of the drought based on SPI, fitting different distribution functions to them and determining the best distribution function for each characteristic, determining one of the most severe historical drought events with the highest value of duration, severity, and peak intensity, and finally using the appropriate Copula functions to estimate the frequency of drought occurrences with the predefined highest values, 2 ) Investigating the effects of climate change using general circulation models (GCM) for future periods, 3) Assessing the return period of the future drought using Copula functions and calculating the characteristics of drought events in the 510 future and drawing spatial maps of the return period of future drought.

511 The SPI was used to calculate the duration, severity, and peak intensity of drought in the basin in the historical period (1979-2008). Among the phenomena that occurred during this period, $90 \%$ of the highest severity, duration, and peak intensity of drought were selected as the benchmark severe drought in the basin. The values included a drought severity with an SPI value of less than (-4.39); drought duration more than 6 months, and peak intensity with an SPI value of less than (-1.36).

Due to the high correlation between drought characteristics, bivariate and tri-variate Cupula 518 joint functions were used to analyze the return period of future droughts in the basin. For this purpose, three types of widely used Cupula functions in the Archimedes family (Frank, Clayton, Gumbel-Hoggard) and two types of the most widely used Cupula functions of the selected based on the BIC method. The effects of climate change on the drought were also investigated using 15 GCM models under RCP4.5 and RCP8.5 scenarios. The future period 
524 was divided into two near future (2016-2057) and the distant future (2058-2099) periods to 525 assess the drought situation.

526 The results of the GCM models under both scenarios for the near and distant future were 527 almost the same and predicted a longer return period for severe drought than in the past. 528 Contrary to this prediction for the basin based on GCM models, due to the uncertainties in 529 climate change forecasting methods, planning for long-term droughts in the basin seems 530 necessary to manage existing water resources.

531 Also, by examining the calculated return period based on different drought parameters in the 532 historical period (1979-2008), the results of the bivariate Copula of the severity- peak 533 intensity can be more compatible with the results of the drought return period based only on 534 one of the variables of severity or the peak intensity of droughts. It appears that the drought 535 duration variable plays an important role in the drought return level in the basin; having 536 increased the continuity of drought duration, the return period of that drought is increased, or 537 in other words, the occurrence frequency is reduced.

538 It is recommended to compare the results of research using AR4 with the current study to find 539 the preference of AR5 in comparison with AR4 in the case of a copula. Also, it is worthwhile 540 to analyze the uncertainty of the prediction by the GCMs and to estimate the probability 541 levels for each model. Besides, it will be advantageous in future studies to analyze the 542 uncertainty of calculated past return periods. 
545 The corresponding author also expresses her gratitude to Shahid Chamran University of 546 Ahvaz, Iran, as well as Virginia Polytechnic Institute and State University, the United States

547 for providing the authors with the facilities and opportunity to complete this study.

\section{Declarations}

549 Ethics approval and consent to participate (Approval was obtained from the ethics com550 mittee of Shahid Chamran University. The procedures used in this study adhere to the tenets 551 of the Declaration of Helsinki

552 Consent for publication (Not applicable)

553 Availability of data and material (All data generated or analysed during this study are 554 available from the corresponding author)

555 Competing interests (The authors declare that they have no competing interests)

556 Funding (Not applicable)

557 Authors' contributions: Material preparation, data collection, study conception, design and 558 analysis were performed by Dr. Elaheh Motevali Bashi Naeini and then it was involved in 559 planning and supervised by Dr. Ali Mohammad Akhoond-Ali and Dr. Fereydoun Rad560 manesh. The first draft of the manuscript was written by Elahe Javadi and then Dr. Jahangir 561 Abedi Koupai commented on previous versions of the manuscript. Dr. Shahrokh Soltaninia 562 verified the analytical methods and performed some calculations. All authors discussed the 563 results and contributed to the final manuscript and approved the final manuscript. 
567 Abdulkadir G (2017) Assessment of Drought Recurrence in Somaliland: Causes, Impacts, 568 and Mitigations. Climatology and Weather Forecasting 5(2): 1-12. DOI: 10.4172/2332

569

570 Ahmadalipour A, Moradkhani H, Demirel M (2017) A comparative assessment of projected

571 meteorological and hydrological droughts: elucidating the role of temperature J. Hydrol 553:

$572785-797$.

573 https://doi.org/10.1016/j.jhydrol.2017.08.047.

574

575 Ayantobo O.O, Li Y, Song S, Yao N (2017) Spatial comparability of drought characteristics

576 and related return periods in mainland China over 1961-2013. J Hydrol 550: 549-567.

577 https://doi.org/10.1016/j.jhydrol.2017.05.019.

578

579 Ayantobo O.O, Li Y, Song S.B (2019) Multivariate drought frequency analysis using four580 variate symmetric and asymmetric Archimedean copula functions. Water Resources Man581 agement 33:103-127.

582

583 Balistrocchi M and Grossi G (2020) Predicting the impact of climate change on urban drain584 age systems in northwestern Italy by a copula-based approach. Journal of Hydrology: Regional Studies 28(10670). https://doi.org/10.1016/j.ejrh.2020.100670Get rights and content.

Barlow M, Zaitchik B, Paz S, Black E, Evans J, Hoell A (2016) A Review of Drought in the 588

Middle East and Southwest Asia. J. Climate 29 (23): 8547-8574. 
590 Bazrafshan J (2017) Effect of Air Temperature on Historical Trend of Long-Term Droughts

591 in Different Climates of Iran. Water Resour Manage 31: 4683-4698.

592 https://doi.org/10.1007/s11269-017-1773-8.

593

594 Ben-Ari T, Adrian J, Klein T, Calanca P, Van der Velde M. Makowski D (2016) Identifying

595 indicators for extreme wheat and maize yield losses. Agric. For. Meteorol 220:130-140.

596 https://doi.org/10.1016/j.agrformet.2016.01.009.

597

598 Chang J, Li Y, Wang Y, Yuan M (2016) Copula-based drought risk assessment combined

599 with an integrated index in the Wei River Basin, China. J. Hydrol 540: 824-834.

600

601 Chatrabgoun, O, Karimi R, Daneshkhah A, Abolfathi, Soroush, Nouri H Esmaeilbeigi M 602 (2020) Copula-based probabilistic assessment of intensity and duration of cold episodes : a 603 case study of Malayer vineyard region. Agricultural and Forest Meteorology. 29 (108150). 604 doi:10.1016/j.agrformet.2020.108150

605

606 Chen L, Singh V.P, Guo S, Mishra AK, Guo J (2012) Drought analysis using copulas. 607 Journal of Hydrologic Engineering 18:.797-808.

608

609 Chen YD, Zhang Q, Xiao M, Singh VP (2013) Evaluation of risk of hydrological droughts by 610 the trivariate Plackett copula in the East River basin (China). Natural Hazards 68:529-47. 611 
612 Daneshkhah A, Remesan R, Chatrabgoun O, Holman I.P (2016) Probabilistic modeling of 613 flood characterizations with parametric and minimum information pair-co-pula model. J. Hy614 drol 540:469-487.

615

616 da Rocha Júnior R.L, dos Santos Silva F.D, Costa R.L, Gomes H.B, Pinto D.D.C, Herdies

617 D.L (2020) Bivariate Assessment of Drought Return Periods and Frequency in Brazilian

618 Northeast Using Joint Distribution by Copula Method. Geosciences 10 (135).

619

620 Das, J., Jha, S., Goyal, M.K., (2019) Non-stationary and copula-based approach to assess the 621 drought characteristics encompassing climate indices over the Himalayan States in India. J. 622 Hydrol 580:124356.

623

624 Dash S.S, Sahoo B, Raghuwanshi, N.S (2019) A SWAT-copula based approach for monitor625 ing and assessment of drought propagation in an irrigation command Ecol. Eng 127: 417626430.

627

628 Favre A. C. El Adlouni S, Perreault L, Thiemonge N, Bobbe B (2004). Multivariate hydro629 logical frequency analysis using copula. Water Resources Research 40(1).

630 https://doi.org/10.1029/2003WR002456

631 Gazol A, Camarero,J.J, Anderegg W. R. L, Vicente-Serrano S. M (2016). Impacts of 632 droughts on the growth resilience of Northern Hemisphere forests. A Journal of Macroecolo633 gy 26 (2): 166-176. 
634 Ge Y, Cai X, Zhu T, Ringle, C (2016) Drought frequency change: an assessment in northern 635 India plains. Agric. Water Manag 176, 111-121.

636

637 Gohari A, Eslamian S, Abedi-Koupaei J, Bavani AM, Wang D, Madani K (2013). Climate 638 change impacts on crop production in Iran's Zayandeh-Rud River Basin Science of the 639 Total Environment 442:405-419.

640

641 Hangshing L and Dabral P. P (2018). Multivariate frequency analysis of meteorological

642 drought using copula. Water Resources Management 32: 1741-1758.

643

644 Hao Z, Hao F, Singh V.P (2016) A general framework for multivariate multi-index drought 645 prediction based on Multivariate Ensemble Streamflow Prediction (MESP). J. Hydrol 539, 164610.

647

648 Hernandez-Barrera S, Rodriguez-Puebla C, Challinor, A.J (2017) Effects of diurnal tempera649 ture range and drought on wheat yield in Spain. Theor. Appl. Climatol 129 (1-2):503-519. 650 https://doi.org/10.1007/s00704-016-1779-9.

651

652 Hoffman MT, Carrick P, Gillson L, West A (2009) Drought, climate change and vegetation 653 response in the succulent karoo, South Africa. South African Journal of Science 105:54-60. 654 
655 Huang L, He B, Han L, Liu J, Wang H, Chen Z (2017) A global examination of the response 656 of ecosystem water-use efficiency to drought based on MODIS data. Sci Total Environ 601657 602: 1097-1107.

658

659 Khan M.M.H, Muhammad N.S, El-Shafie A (2018) A review of fundamental drought con660 cepts, impacts and analyses of indices in Asian continent. J. Urban Environ. Eng 12:106-119. 661

662 Kiafar H, Babazadeh H, Sedgh Saremi,A (2020) Analyzing drought characteristics using 663 copula-based genetic algorithm method. Arab J Geosci 13(745).

664 https://doi.org/10.1007/s12517-020-05703-1.

665

666 Kirono D, Kent D, Hennessy K, Mpelasoka F (2011) Characteristics of Australian droughts 667 under enhanced greenhouse conditions: Results from 14 global climate models. Journal of 668 Arid Environments 75:566-75.

669 Kown H.H and Lall U (2016) A copula-based nonstationary frequency analysis for the 20126702015 drought in California. Water Resources Research.52(7): 5662-5675.

671 Lee T, Modarres R, Ouarda T (2013) Data-based analysis of bivariate copula tail dependence 672 for drought duration and severity. Hydrological Processes 27:1454-63.

674 Lee,S.-H, Yoo S.-H, Choi J.-Y, Bae S (2017) Assessment of the Impact of Climate Change 675 on Drought Characteristics in the Hwanghae Plain, North Korea Using Time Series SPI and 676 SPEI: 1981-2100. Water 9(579). 
678 Li C, Singh, VP, Mishra AK (2013) A bivariate mixed distribution with a heavy-tailed 679 component and its application to single-site daily rainfall simulation. Water Resources 680 Research 49:767-89.

681

682 Liu Z.P, Wang Y.Q, Shao M.G, Jia X.X, Li X.L (2016) Spatiotemporal analysis of mul683 tiscalar drought characteristics across the Loess Plateau of China. J. Hydrol 534:281-299.

684

685 Luo, Y., Dong, Z.., Guan, X., Liu, Y (2019) Flood Risk Analysis of Different Climatic Phe686 nomena during Flood Season Based on Copula-Based Bayesian Network Method: A Case 687 Study of Taihu Basin, China. Water. 11(1534).

688

Ma M, Ren L, Singh V.P, Yuan F, Chen L, Yang X, Liu Y (2016) Hydrologic model-based 690 Palmer indices for drought characterization in the Yellow River basin, China. Stoch Environ

Res Risk Assess 30: 1401-1420. https://doi.org/10.1007/s00477-015-1136-Z.

Madadgar S and Moradkhani H (2011) Drought analysis under climate change using copula. Journal of Hydrologic Engineering 18:746-59.

694

McKee TB, Doesken NJ, Kleist J (1993) The relationship of drought frequency and duration to time scales. Proc. Proceedings of the 8th Conference on Applied Climatology. American Meteorological Society Boston. MA 17:179-83.

698 of meteorological drought in northwest Iran using the Joint Deficit Index. Journal of Hydrology 492:35-48. 
703 Montaseri M, Amirataee, B, Rezaie, H (2018) New approach in bivariate drought duration 704 and severity analysis. J. Hydrol 559:166-181. https://doi.org/10.1016/j.jhydrol.2018.02.018. 705

706 Mousavi S-F (2005) Agricultural drought management in Iran. Proc. Water Conservation, 707 Reuse, and Recycling: Proceedings of an Iranian-American Workshop. National Academies 708 Press pp.106-13.

709

710 Mukherjee S, Mishra A, Trenberth K.E (2018) Climate Change and Drought: a Perspective 711 on Drought Indices. Curr Clim Change Rep 4: 145-163. https://doi.org/10.1007/s40641-018712 0098-x.

713 Nelsen RB (2007) An introduction to copulas. Springer Science \& Business Media.

714

715 Oguntunde P.G, Abiodun B.J, Lischeid G (2017) Impacts of climate change on hydro716 meteorological drought over the Volta Basin, West Africa. Glob. Planet. Change. 155: 121$717 \quad 132$.

718

719 Páscoa P, Gouveia, C.M., Russo A, Trigo R.M (2017) The role of drought on wheat yield in720 terannual variability in the Iberian Peninsula from 1929 to 2012. Int. J.Biometeorol. 61 (3): 721 439-451. https://doi.org/10.1007/s00484-016-1224-x. 
723 Ribeiro A.F.S, Russo A, Gouveia C.M, Páscoa P (2019) Modelling drought-related yield 724 losses in Iberia using remote sensing and multiscalar indices. Theor Appl Climatol 136:203725 220. https://doi.org/10.1007/s00704-018-2478-5

726

727 Ribeiro A.F.S, Russo A, Gouveia C.M, Páscoa, P (2019) Copula-based agricultural drought 728 risk of rainfed cropping systems. Agric. Water Manag 223(105689).

729

730 Sabzevari A.A., Miri G., Mohammadi Hashem M (2013) Effect of Drought on Surface Water

731 Reduction of Gavkhouni Wetland in Iran. Journal of basic and scientific research 3(2s):116732119.

733

734 Safavi, HR. Esfahani, MK. Zamani, AR (2014) Integrated index for assessment of 735 vulnerability to drought, case study: Zayandehrood River Basin, Iran. Water Resources 736 Management 28:1671-88.

737

738 Santos, C.A.C., Perez-Marin, A.M., Ramos, T.M., Marques, T.V., Lucio, P.S., Costa, G.B., 739 Santos e Silva, C.M., Bezerra, B.G (2019) Closure and partitioning of the energy balance in a 740 preserved area of Brazilian seasonally dry tropical forest. Agric. For. Meteorol. 271, 398741 412. https://doi.org/10.1016/j.agrformet.2019.03.018.

743 Selvaraju, R. Baas, S (2007) Climate Variability and Change: Adaptation to Drought in 744 Bangladesh: a Resource Book and Training Guide. Food \& Agriculture Org. 
746 Shiau J (2006) Fitting drought duration and severity with two-dimensional copulas. Water

747 Resources Management 20:795-815.

748

749 Thilakarathne, M., Sridhar, V (2017) Characterization of future drought conditions in the

750 Lower Mekong River Basin. Weather Clim. Extremes 17: 47-58.

751

752 Thomas, J. and Prasannakumar, V (2016) Temporal analysis of rainfall (1871-2012) and

753 drought characteristics over a tropical monsoon-dominated State (Kerala) of India. J. Hydrol

$754 \quad 534: 266-280$.

755

756 Thrasher, B. Xiong, J. Wang, W. Melton, F. Michaelis, A. Nemani, R (2013) Downscaled

757 climate projections suitable for resource management. Eos. Transactions American of 758 Geophysical Union. 94:321-323.

759

760 Tian L, Yuan S, Quiring S.M. (2018) Evaluation of six indices for monitoring agricultural

761 drought in the southcentral United States. Agric. For. Meteorol 249:107-119.

762 Tsakiris G, Kordalis N, Tigkas D, Taskiris V, Vangelis H (2016) Analysing Drought Severity

763 and Areal Extent by 2D Archimedean Copulas. Water Resour Manage 30:5723-5735.

764 https://doi.org/10.1007/s11269-016-1543-z

765

766 Wayne G (2013) The beginner's guide to representative concentration pathways. skeptical

767 science. Version 1.0. http://www.skepticalscience.com/rcp.php. 
769 World Meteorological Organization, (2012) Standardized Precipitation Index User Guide (M.

770 Svoboda, M. Hayes and D. Wood). (WMO-No. 1090), Geneva.

771

772 Wu J.F, Chen X.W, Yao H.X, Gao L, Chen Y, Liu, M.B (2017) Non-linear relationship of

773 hydrological drought responding to meteorological drought and impact of a large reservoir. J.

774 Hydrol. 551: 495-507.

775

776 Xu K, Yang D, Xu X. Lei H (2015) Copula based drought frequency analysis considering

777 the spatio-temporal variability in Southwest China. Journal of Hydrology 527:630-40.

778

779 Yan J (2007) Enjoy the joy of copulas: with a package copula. Journal of Statistical Software 780 21:1-21.

781

782

783

784

785

786

Yang W (2010) Drought analysis under climate change by application of drought indices and copulas, Dissertations and Theses, Portland State University, Portland. 716P.

787

788

Zampieri M, Ceglar A, Dentener F, Toreti, A (2017) Wheat yield loss attributable to heat

789 waves, drought and water excess at the global, national and subnational scales. Environ. Res.

790 Lett 12 (6). 064008. https://doi.org/10.1088/1748-9326/aa723b. 
792 Zhang L, Singh V. P (2007) Gumbel Hougaard copula for trivariate rainfall frequency analy793 sis. J. Hydrol. Eng 12(4): 409-419. https://doi.org/10.1061/(ASCE)1084-

$794 \quad \underline{0699(2007) 12: 4(409)}$.

795

796 Zhang D, Chen P, Zhang Q, Li X (2017) Copula-based probability of concurrent hydrological 797 drought in the Poyang lake-catchment-river system (China) from 1960 to 2013. J. Hydrol $798 \quad 553: 773-784$.

799

800 Zhu Y, Liu Y, Wang W, Singh V. P, Ma X, Yu Z (2019) Three dimensional characterization 801 of meteorological and hydrological droughts and their probabilistic links. Journal of Hydrol802 ogy 578(124016). 


\section{Figures}

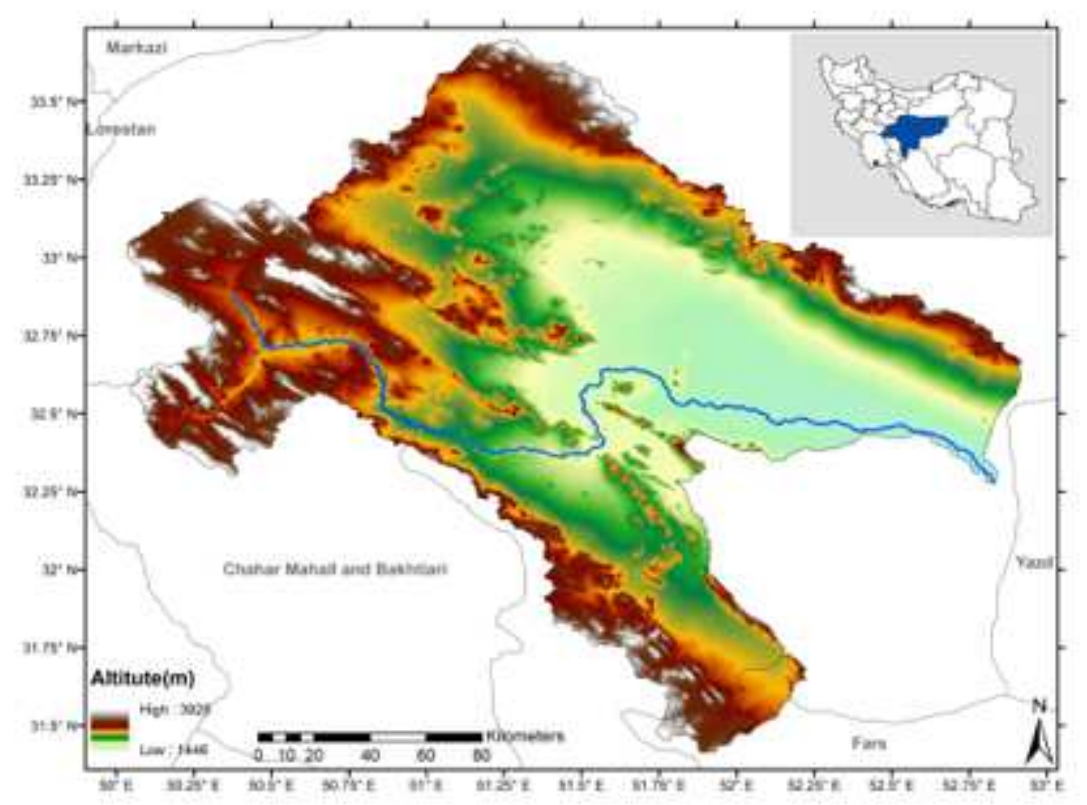

Figure 1

Geographic location of the Zayandeh Rud basin. Note: The designations employed and the presentation of the material on this map do not imply the expression of any opinion whatsoever on the part of Research Square concerning the legal status of any country, territory, city or area or of its authorities, or concerning the delimitation of its frontiers or boundaries. This map has been provided by the authors.
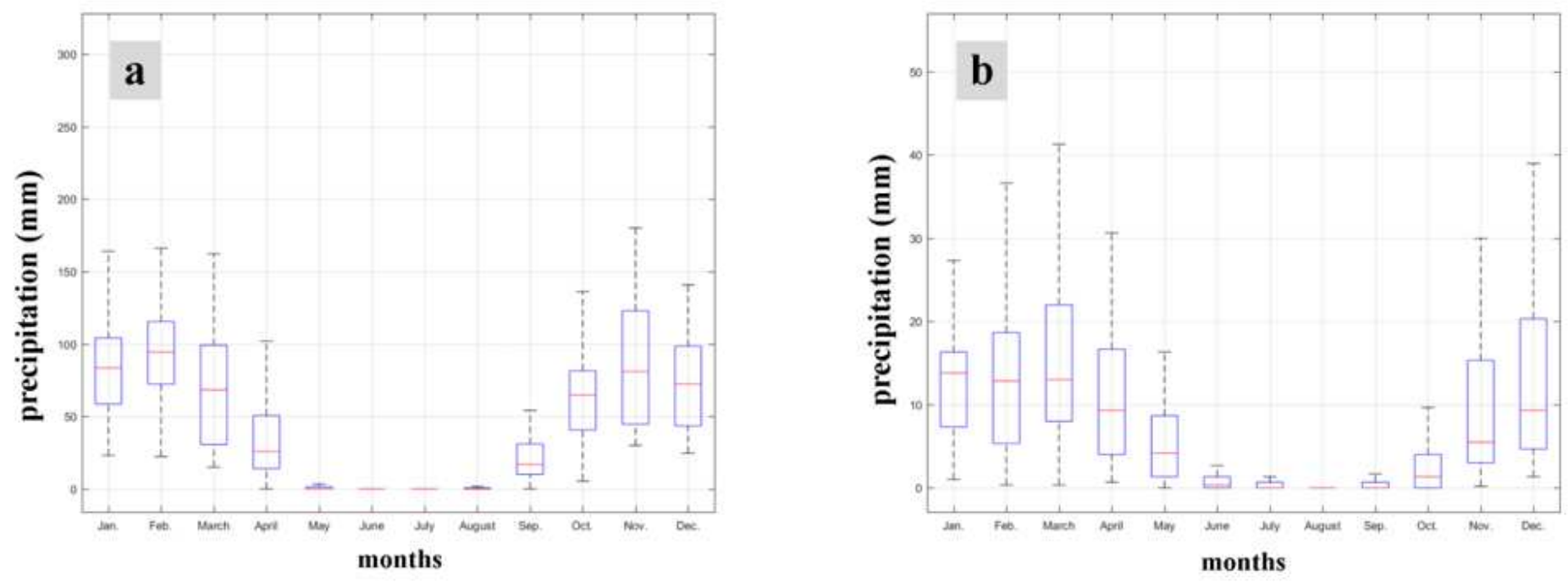

Figure 2 
Changes in monthly precipitation in the past (1979-2008): a) station located upstream b) station located downstream

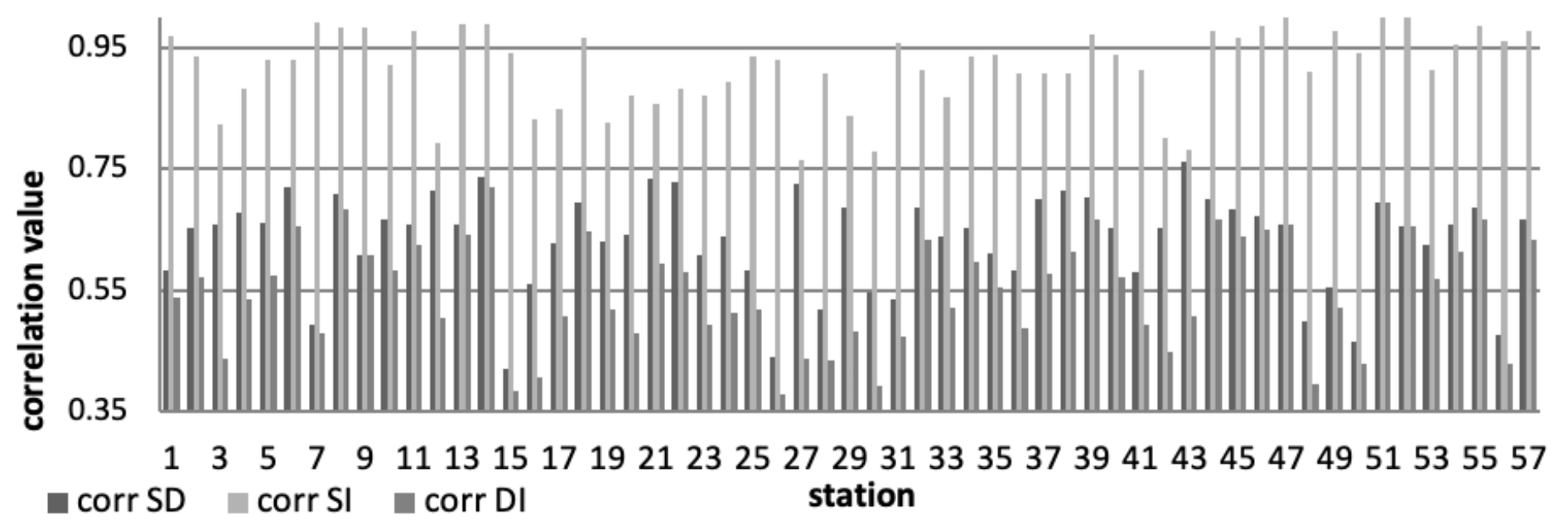

Figure 3

Linear correlation between drought characteristics (S indicates severity, D indicates duration, and I indicates the peak intensity of drought in each period.) 


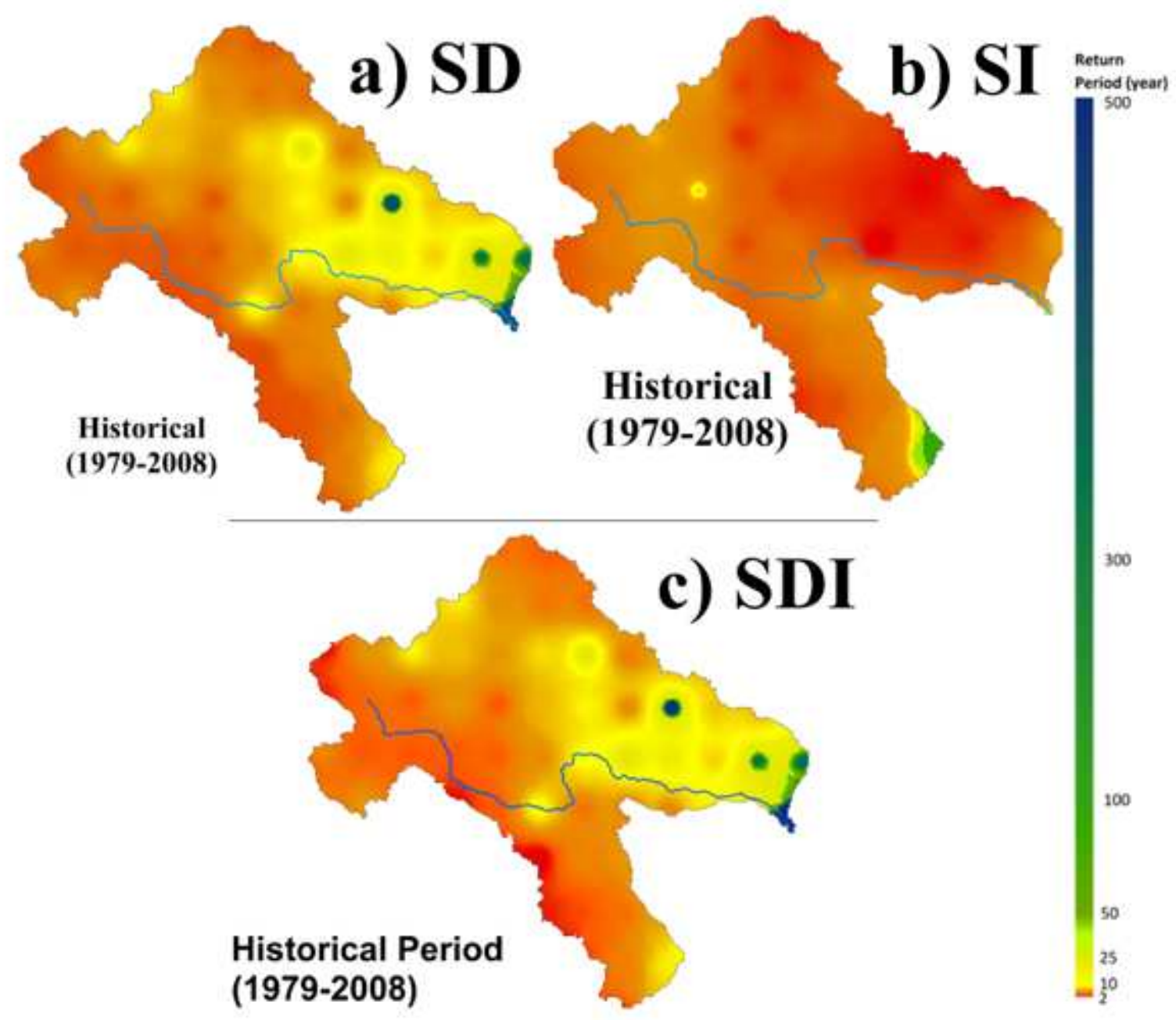

Figure 4

Comparison of the calculated return period of the severe drought using tri-variate and bivariate copula functions in the historical period (1979-2008) a) SD: bivariate copula of Severity-Duration b) SI: bivariate copula of Severity-Peak intensity and c) SDI: tri-variate copula of Severity-Duration-Peak intensity. 

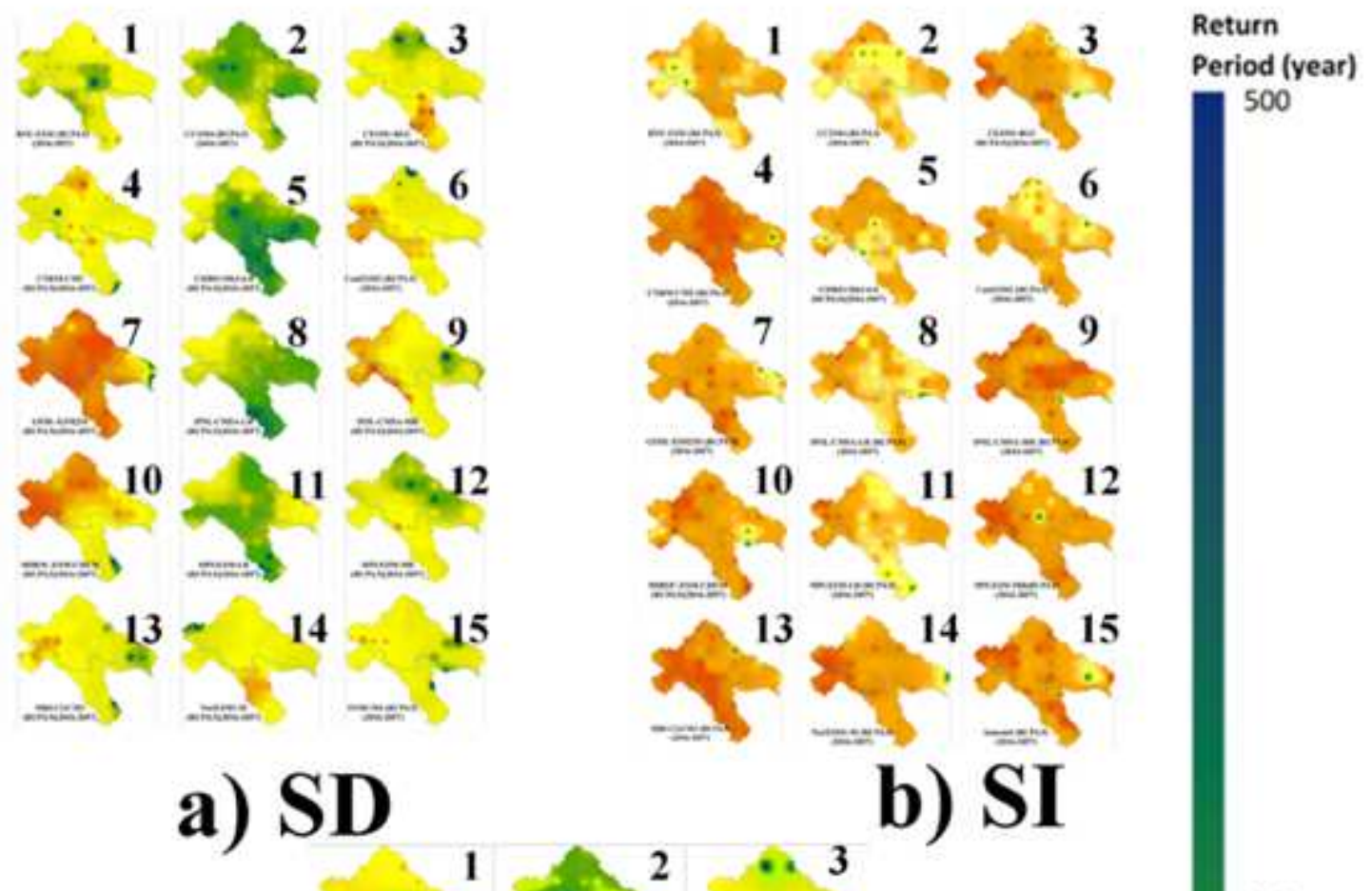

a) SD

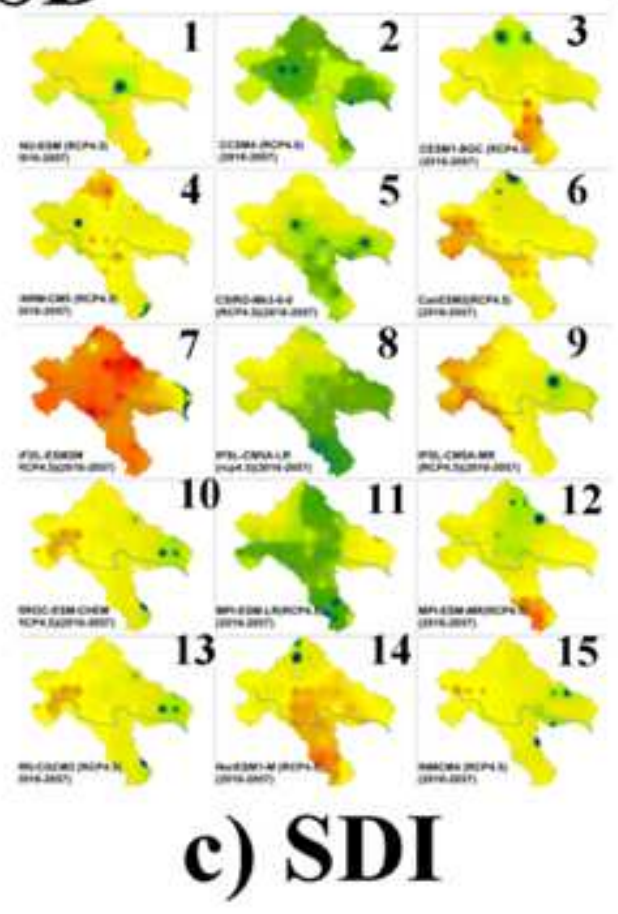

300

\section{Figure 5}

Comparison of the calculated return period of the severe drought using tri-variate and bivariate copula functions in the near future (2016-2057) using 15 GCMs with RCP4.5 a) SD: bivariate copula of SeverityDuration b) SI: bivariate copula of Severity-Peak intensity and c) SDI: tri-variate copula of SeverityDuration-Peak intensity. 


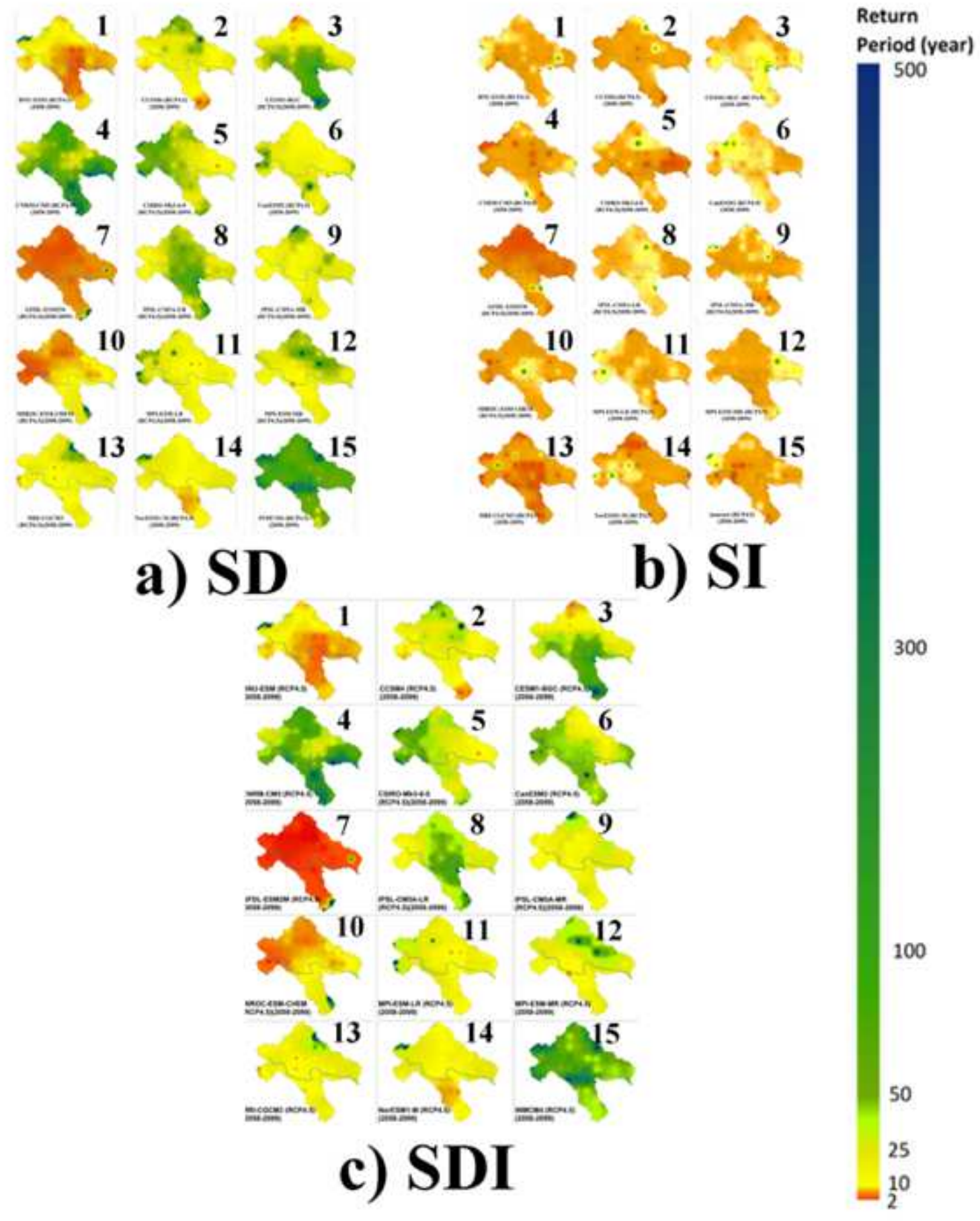

Figure 6

Comparison of the calculated return period of the severe drought using tri-variate and bivariate copula functions in the distant future (2058-2099) using 15 GCMs with RCP4.5 a) SD: bivariate copula of Severity-Duration b) SI: bivariate copula of Severity-Peak intensity and c) SDI: tri-variate copula of Severity-Duration-Peak intensity. 


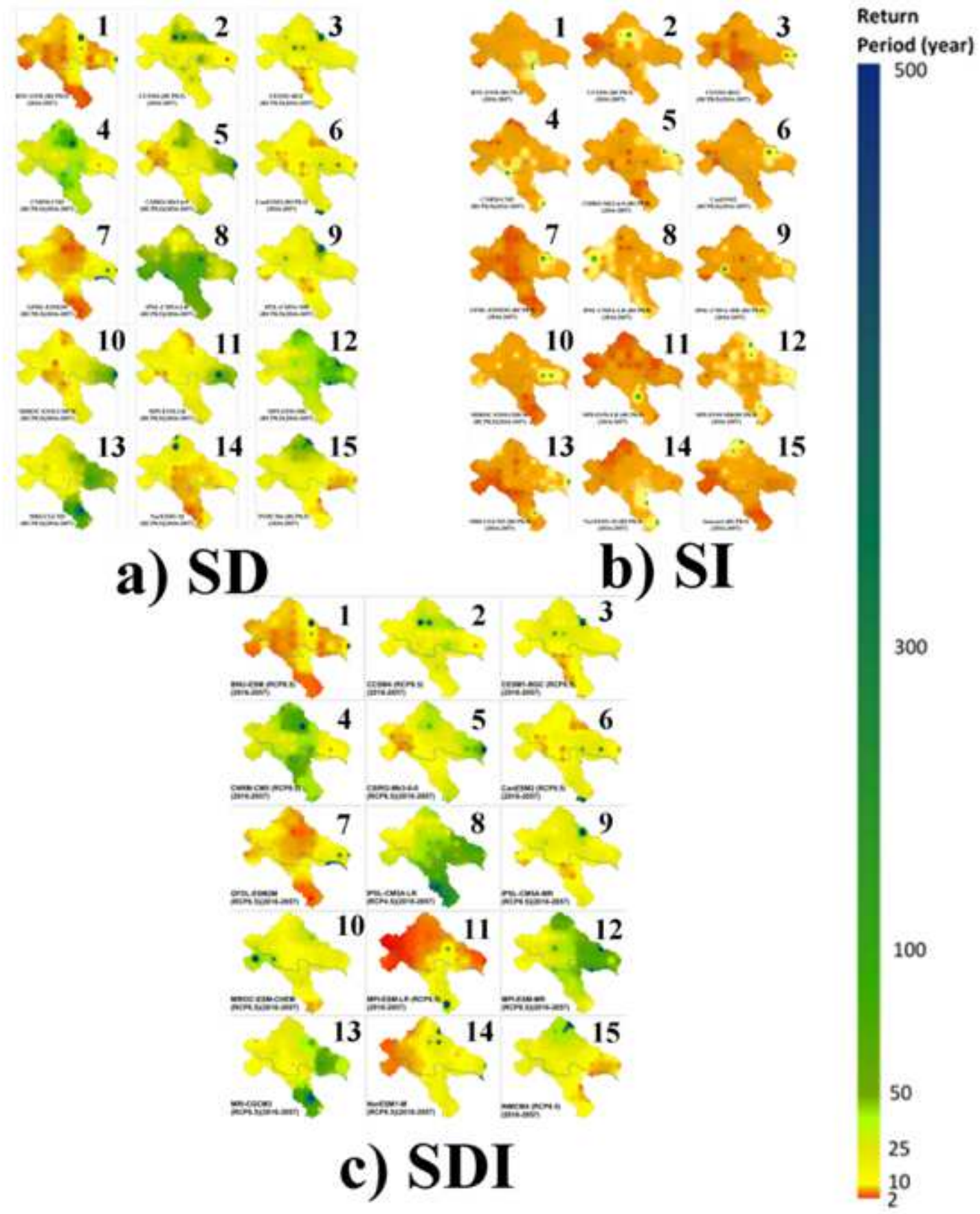

Figure 7

Comparison of the calculated return period of the severe drought using tri-variate and bivariate copula functions in the near future (2016-2057) using 15 GCMs with RCP8.5 a) SD: bivariate copula of SeverityDuration b) SI: bivariate copula of Severity-Peak intensity and c) SDI: tri-variate copula of SeverityDuration-Peak intensity. 


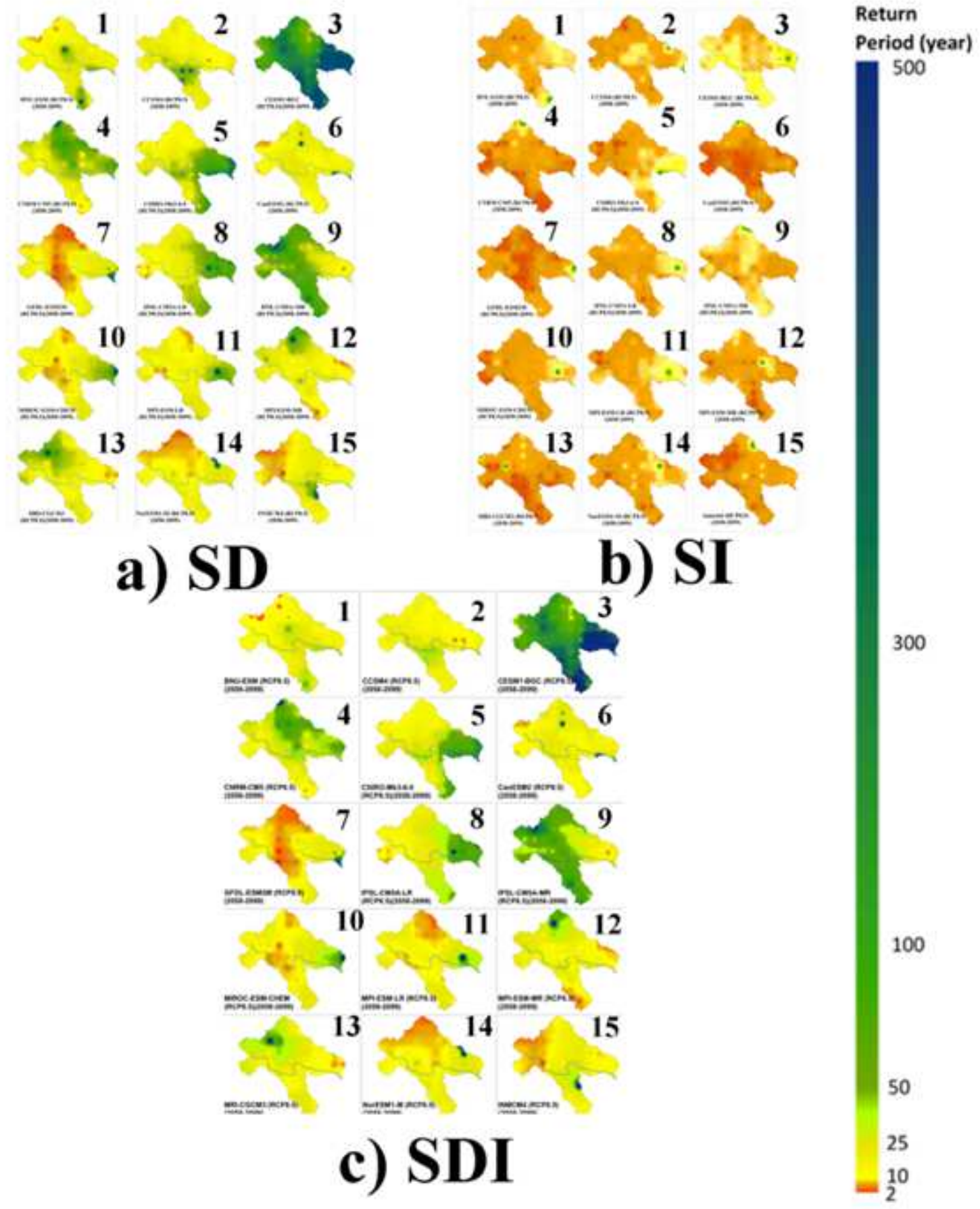

Figure 8

Comparison of the calculated return period of the severe drought using tri-variate and bivariate copula functions in the distant future (2058-2099) using 15 GCMs with RCP8.5 a) SD: bivariate copula of Severity-Duration b) SI: bivariate copula of Severity-Peak intensity and c) SDI: tri-variate copula of Severity-Duration-Peak intensity. 


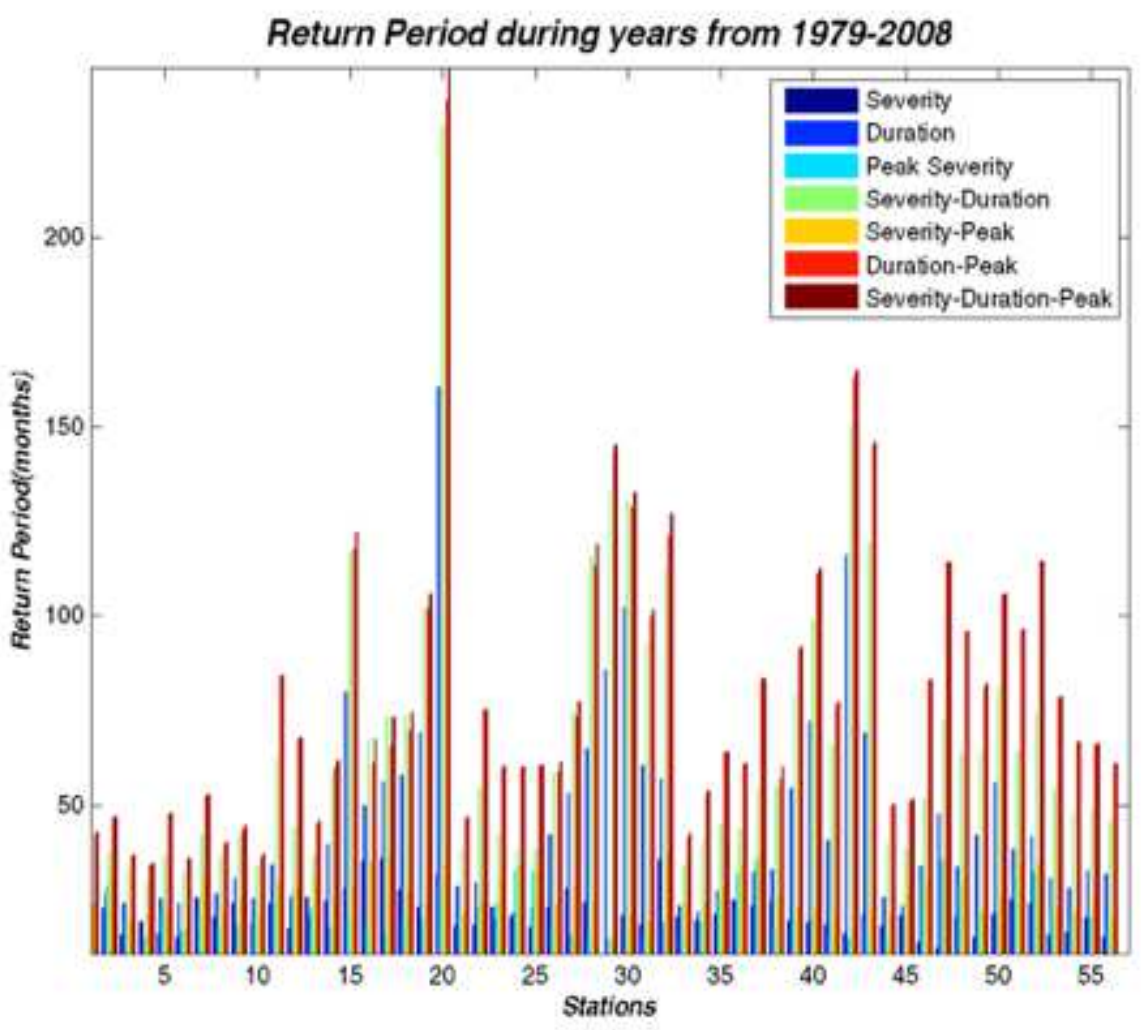

Figure 9

Return period of severe drought based on various drought parameters in the Historical Period (19792008) 